\title{
THICK-WALLED COMPOSITE TUBES FOR OFFSHORE APPLICATIONS: \\ AN EXAMPLE OF STRESS AND FAILURE ANALYSIS \\ FOR FILAMENT-WOUND MULTI-LAYERED PIPES
}

\author{
Marina MENSHYKOVA, Igor A. GUZ* \\ Centre for Micro- and Nanomechanics (CEMINACS), School of Engineering, \\ University of Aberdeen, Aberdeen AB24 3UE, Scotland, UK \\ E-mails: m.menshykova@abdn.ac.uk; i.guz@abdn.ac.uk
}

Jeom Kee PAIK

The Korea Ship and Offshore Research Institute, Pusan National University, South Korea

\begin{abstract}
The paper reviews practical applications of composite materials in oil and gas industry. A special consideration has been paid to possible future opportunities in offshore and onshore usage; in particular to long fibre reinforced composite pipes. The problem of thick-walled filament-wound multi-layered composite pipes subjected to outer pressure is considered as an example. An analytical method is used for failure analysis for different lay-ups and loading conditions. The stress distributions through the pipe thickness for various lay-ups are computed for fibre reinforced pipes under different outer pressure magnitudes.
\end{abstract}

Key words: fibre reinforced composite, thick-walled pipe, pressure loading, stress and failure analysis.

* Corresponding author. Tel.: +44 (0)1224 272808; e-mail: i.guz@abdn.ac.uk 


\section{Introduction}

Having advantages over conventional materials in weight, strength, stiffness, corrosion resistance composite materials are becoming more and more attractive for structural and non-structural applications in the oil and gas industry. However, in spite of their undoubted advantages, the main of which may be the ability to be tailored for specific purpose, their introduction in the industry is a very slow process. Lack of appropriate performance information, regulatory requirements, efficient design procedures and reparability issues are the main obstacles.

\subsection{Use of composites in oil and gas industry}

Fibre reinforced composites are the alternatives of steel, metal and wood in many applications. This may be due to their high specific tensile and compressive strength, good fatigue and corrosion resistance and their suitability for the production of complex-shape components with reduced manufacture times compared to conventional metallic materials. Ease of handling, high adaptability, economy of fabrication, and damage tolerance are the driving force of the application of the fibre reinforced composite materials.

High specific strength as well as overall weight-saving and resistance to a wide range of fluids (including seawater, aerated water, $\mathrm{H}_{2} \mathrm{~S}, \mathrm{CO}_{2}$, and hydrocarbons) which can attack metals results in growing interest in their use for applications within the oil and gas sector. The areas within the oil industry, where the composites are used include rigid pipework, coiled tubing, rigid and flexible risers, structural repairs and others. Gibson (2000) described composite pipework as one of the most established uses of composites within the oil and gas industry. One of the more recent papers on the topic was published by Taheri (2013), where fibre-reinforced composites for pipes and tanks manufacture and rehabilitation in oil and gas industry were considered. The author also outlined various applications of the FRPs in relation to pipes and risers.

The exploitation of GFRP offshore was inhibited by the knowledge that the strength of most GFRP systems is reduced at elevated temperature and by the absorption of water. The results of the tests conducted to characterize the strength reduction of three GFRP composite materials as a function of temperature and testing environment can be found in Hale and Gibson (1998). Gu (2009a, 2009b) considered the behaviour of glass fibre reinforced unsaturated polyester laminates fabricated by using the vacuum assisted resin infusion technique after immersing in the artificial seawater for different durations of time. The biaxial failure envelope and creep testing of GFRP in high temperature (up to $160^{\circ} \mathrm{C}$ ) liquids were investigated by Hale et al. (2002). The tests were made on dry and after exposure to saturation in

various working environments (sea water, crude oil, water with dissolved $\mathrm{CO}_{2}$ and water with dissolved $\mathrm{H}_{2} \mathrm{~S}$ ) specimens, highlighting the sensitivity to loading direction with respect to fibre orientation. 
The corrosive behaviour of PMC (polymer matrix composite) structure is much better than the steel structure in the marine environment. In view of the wide application of polymeric composites in offshore structures, submersibles and highway infrastructure, the effect of seawater on deformation, strength and durability of materials was considered by Weitsman and Elahi (2000). The effect of moisture absorption on the compressive, tensile, and shear behaviours of PMC has been investigated by many researchers (Russell and Street (1989); Ogi and Takeda (1997); Weitsman (1998); Togo et al. (2000); Davies and Carlsson (2009)). It is known from their research results that moisture absorption causes plasticization and swelling of the epoxy, weakening the interfacial strength between fibres and epoxy, which results in the reduction of tensile and shear strength. However, the effect of moisture absorption on fracture behaviour is different depending on the studies conducted.

Deniz et al. (2013) experimentally investigated the effect of seawater on failure pressure and impact behaviours of glass-epoxy pipes. The effect of seawater absorption on the interlaminar fracture behaviour of carbon/epoxy composites was investigated by Sloan and Seymour (1992). The effect of hydrostatic pressure on the compressive and shear behaviour of carbon/epoxy composites was considered by Shin and Pae (1992a, 1992b), Pae and Rhee (1995), Rhee and Pae (1995). The tensile behaviour of carbon/epoxy composites under a hydrostatic pressure environment was investigated by Zinoviev et al. (2001). It is generally accepted that the tensile and compressive strengths of polymeric composites increase as the applied hydrostatic pressure increases.

The combined effect of seawater absorption and hydrostatic pressure on the mechanical behaviour of PMC materials was considered by Rhee et al. (2004, 2006). For this purpose, fracture tests were performed using seawaterabsorbed carbon/epoxy composite, whose seawater absorption capability was at a maximum absorption level, in a hydrostatic pressure environment. Compliance, fracture load and fracture toughness were determined as a function of applied hydrostatic pressure. After the fracture tests were performed, optical microscope examination was made on the fracture surfaces to determine the fracture mechanism of carbon/epoxy composites in a deep-sea environment. Comparative study of dry and seawater absorbed specimens showed that seawater-absorbed specimen has a lot more epoxy fracture than the dried one. There is a clear need in more precise modelling of underwater compressive behaviour of composites. It can be achieved, in particular, by incorporating into the modelling the exact analytical solutions developed by Guz (1998), Soutis and Guz (2001), Guz and Herrmann (2003), Guz and Rushchitsky (2004), Guz et al. (2008), Menshykova et al. (2009) and others.

Composite cylinders are widely used in oil industry, designed to resist either internal pressure (e.g. fluid transport and storage, cooling systems) or external pressure (e.g. underwater or downhole applications). One of the main concerns with these structures is the propagation of interlaminar defects, produced during manufacture or service. Understanding the factors affecting the delamination resistance of the laminate used in the cylinders is essential if their safe working envelope is to be defined. In the work by Davies and Carlsson (2009) the influence of winding angle was 
examined in order to optimize cylinder performance. In the paper the delamination resistance of filament wound composite cylinders and the influence of delamination damage on the failure of externally pressurized composite cylinders were considered. Pressure tests on cylinders without implanted defects and with impact damage and implanted defects to simulate fabrication and in-service damage, were performed. A series of external pressure tests was performed on the glass/epoxy, carbon/epoxy and carbon/PEEK cylinders to examine the influence of different types of delaminations.

Full-scale application of composites in rigid risers is expected within the next decade. Since risers operate in seawater, effects of seawater are examined by aging carbon and glass reinforced epoxy laminates of different thickness and lay-up orientation at temperature experimentally (Grant and Bradley 1995; Ochoa and Ross 1998). The analytical scaling methodology that depends on the geometry, constituent material properties as well as location, orientation hybridization of the reinforcing fibres was developed but not verified for full scale composite tubes (Chouchaoui and Ochoa 1999; Rodriguez and Ochoa 2004). This information is particularly important for another class of risers hybrid flexible tubulars which are in various stages of maturity in the oil industry. These risers are either fully filament wound composites with thermoplastic matrix or have stainless steel internal carcass with an extruded polymer fluid barrier, a carbon steel interlocked hoop strength layer, and helically wound composite tensile armour (e-glass, aramid, carbon fibres). Flexible risers are the tubes which achieve their flexibility by virtue of the fact that the load-bearing components are free to move relative to one another. There are significant opportunities for the use of unidirectional carbon fibre composite elements, which may be either thermoplastic or thermoset-based, in the armour for weight-saving, and because of corrosion problems with steel. This could represent a significant future application for composites (Gibson 2000).

The other use of composite materials in offshore industry is the insulation coating of the production infrastructure at great depths. To limit heat losses and so avoid the formation of hydrate and wax plugs inside subsea production flowlines or risers under high pressure and low external temperature conditions, even during production shutdowns, the pipelines need to be thermally insulated. One of the most efficient types of thermal insulation systems is the multilayered structure made of several materials of different thicknesses directly applied to the external surface of the steel pipe. Currently used materials in thermal insulating multilayered systems for deep sea applications include massive polymers and syntactic foams, composed of hollow glass microspheres embedded in a polymer matrix. These composites must combine thermal insulation function, low buoyancy while providing good compressive strength. Syntactic foam coatings are expected to fulfil today's challenges as pipelines are required to operate in more and more severe conditions. Syntactic foam is a lightweight composite material made from tiny hollow microspheres in a polymeric resin binder, along with other fillers and additives. Because the micro-spheres are filled with air, syntactic foam is low in both density and thermal conductivity. Typically, the choice of syntactic materials includes rigid binders 
and flexible binders. Rigid binders add support and reinforcement to the micro-spheres, giving greater strength. The most common rigid binder resin choice is epoxy, because of its superior strength and resistance to hot and wet conditions. However, excessive rigidity may result in cracking under thermal shock and cycling. Flexible binders reduce this prospect. Flexibility is desirable in many applications, and can offer some protection against cracking. However, flexible binders must be carefully designed to avoid degradation under hot, wet conditions, and they do not strongly reinforce micro-sphere fillers, detracting from their effectiveness in density and thermal conductivity (Song et al. 2005; Sauvant-Moynot et al. 2006, 2007; Bouchonneau et al. 2007, 2010; Grosjean et al. 2009).

Composite spoolable or coiled tubing is also intensively utilized technology in oil industry. (Composite coiled or spoolable tubing refers specifically to Fiberspar and similar products.) Spoolable tube is thick-walled pipe which must withstand number of loads such as bending, thermal, axial loads, internal and external pressure etc. Tubing of this type can only be coiled by allowing the matrix to crack extensively, i.e. a brittle matrix composite is used with the matrix in an almost completely cracked condition. Of course, such a tube would leak unless it is equipped with a thermoplastic liner. With the increasing length of the boreholes the use of steel coiled tubing is limited by tensile load capacity, combined allowed axial force and pressure and tube dimension. Composite coiled tubing allows overcoming the steel coiled tubing limited working depth problem as they have such advantages as being lightweight, possessing high strength and low density. The coiled tube itself is the thick-walled pipe of several kilometres length. Consequently the continuous manufacturer processes such as pultrusion, pull winding or pull braiding technique is used for fibre reinforced composite coiled tubing fabrication. One of the applications of coiled tubing in oil industry is well intervention operation. To use composite coiled tubing for high-pressure down-hole applications it must be capable to withstand a high working pressure, high temperature, bending and axial load.

The humid ageing of syntactic foams under hydrostatic pressure, up to $100 \mathrm{MPa}$, has been widely studied (Watkins 1988, Fine et al. 2003). But the combination of high pressure/high temperature conditions (up to 30 $\mathrm{MPa} / 130{ }^{\circ} \mathrm{C}$ ) is a recent concern: a pioneering research program including ageing in hot wet conditions has shown that traditional industrial syntactic foams were undergoing rapid and severe degradation in seawater at temperatures as low as $60{ }^{\circ} \mathrm{C}$ (Choqueuse 2002). There is experimental evidence that a key factor may be the chemical degradation of glass microspheres due to the "entrance” of water (Kochetkov 1996).

Functionally graded materials (FGMs) are becoming increasingly viable thanks to polymer composite materials. Syntactic foams have become attractive for aerospace and marine applications owing to low density, high water resistance and high strength offering a variety of options for the designer for creating property gradients. Threedimensional elasticity solution for a functionally graded simply supported plate subjected to transverse loading was obtained by Kashtalyan (2004). Several analytical and numerical studies are available on statically loading, impact loading, free vibration and thermoelasticity analysis of FG core sandwich panels. A paper by Kashtalyan and 
Menshykova (2009) presents a three-dimensional elasticity analysis of sandwich panels with a FG core subjected to transverse loading.

The application of composites in subsea industry is based on thermoset matrix composites, mainly epoxies. Potentially thermoplastic composites can replace these. In (Davies et al. 2005) the results from preliminary screening tests on the selection of thermoplastic composite materials were obtained. Based on these results glass/PEI and carbon/PEEK materials were selected for further evaluation.

Composites are routinely used to repair metal structures as damaged or corroded pipelines. These repairs have been a common practice in oil industry and are generally easier and faster to carry out comparing to traditional metallic method. At the moment the research is focused on the development of effective subsea composite repair systems and was investigated by Alexander (2007), Shamsuddoha et al. (2013), Mally et al. (2013). The effectiveness of FRP composites for the subsea repair of steel pipeline was analysed by Shamsuddoha et al. (2013). The performance of a carbon/epoxy repair installed and cured underwater has been tested by Mally et al. (2013).

\subsection{Fibre reinforced composite pipes}

The composite pipes from glass fibre reinforced epoxy (GFRE) have been used onshore for both low- and high-pressure applications with a wide variety of fluids, including hydrocarbons. Offshore glass-fibre reinforced resin matrix composites are used for relatively low-pressure aqueous services. The effect of water absorption of the mechanical behaviour of fibreglass pipes used for offshore service waters was considered in d'Almeida (2008). Considering the fact that GFRE has the high specific strength and corrosion resistance, which make it ideal for the petrochemical industry, the use it offshore likely to change in the future (Gibson 2000). However, the wall thickness of high-pressure GFRE pipe tends to be inconvenient for manufacture and handling, because of the high effective safety factor on GFRE pipe. The development of steel strip laminate overcomes the problem (Friedrich1999). The effect of artificial seawater on the impact behaviour of filament-wound GRE pipes has been experimentally studied by Deniz and Karakuzu (2012).

Since the properties of the fibre composite are different along the fibre and in transverse direction, the properties of the filament wound composite pipe can be easily changed by changing the number of winding angles and the fibre direction in each layer. The studies of thin-walled fibre-reinforced composite pipes were made by a number of researchers. Works of Hull et al. (1978), Spencer and Hull (1978), Uemura and Fukunaga (1981), Rosenow (1984), Soden et al. (1989), Mistry et al. (1992) show that the winding angle plays an important role in filament-wounded pipes design. The failure processes of thin-walled glass-reinforced polyester pipes wounded at "ideal angle" of $55^{0} 44^{\prime}$ were studied by Hull et al. (1978). The series of closed-end and unrestrained end internal pressure tests to failure of the pipes were conducted. In their next work Spencer and Hull (1978) extended their initial investigation and consider pipes wound at $35^{\circ}, 45^{\circ}, 65^{\circ}$ and $75^{\circ}$. Their investigation showed a pronounced effect of the winding angle on the micro- 
mechanisms associated with deformation, weepage and fracture. Rosenow (1984) considered filament-wound pipes wounded at six different angles under different types of loading: biaxial pressure, hoop pressure and tensile loading. Comparing the results with classical lamination theory he got good agreement between theory and experiment. His investigation showed that the optimal winding angle depends primary on state of loading and should be $54.75^{\circ}$ for biaxial pressure loading, $75^{0}$ for hoop pressure loading and the lowest possible angle for tensile loading. Soden et al. (1989) considered $\pm 55^{\circ}$ thin-walled filament wounded tubes under combinations of internal pressure and axial tensile and compressive loads to get the failure envelope. The buckling behaviour of $\pm 55^{0}$ filament wound pipes under combinations of external pressure and axial loading were considered by Mistry et al. (1992). The analytical procedure for the orthotropic cylindrical shells was developed by Wild and Vickers (1997). The procedure allows assess the stresses and deformations of filament-wound structures and the effect of wind angle. Their procedure is based on the Leikhnitskii (1981) solution for the problem of plane stresses in multi-layered thin circular cylindrically orthotropic shell.

The studies mentioned above were focused on thin-walled cylindrical fibre reinforced structures. The number of studies on the behaviour of thick-walled fibre reinforced tubular structures is more limited.

Thermal stress analysis of a thick fibre reinforced laminated rings was made by Ajit (1991). Rodriguez and Ochoa (2004) have presented an evaluation of the behaviour of filament-wound spoolable composites. A combination of 4-point bending testing and FEA was used to determine minimum spool radii. An analytical solution for design and analysis of laminated composite tubes is given by Starbuck and Eberle (2000). Xia et al. (2002) considered the thickwalled sandwich pipe with nonreinforced core layer and alternate-ply skin layers. In the paper the method for stressstrain deformation under pure bending analysis is presented. The theoretical approach for the strength and failure mode prediction of filament-wound composite pipes under bending load was considered (Natsuki et al. 2003). Stress distribution in spoolable fibre reinforced composite pipes was investigated by Menshykova and Guz (2013). The cyclic internal pressure and temperature loading was considered by Ansari et al. (2010). The stress analysis of multi-layered filament-wound composite pipes was carried out obtaining the time-dependent stress, strain and deformation distribution. The analytical method to study the mechanical response of thick-walled composite pipe subjected to internal pressure was proposed by Bouhafs et al. (2012). The effect of random design variables on the pipe behaviour was analysed in the paper. Xia, Takayanagi and Kemmochi (2001) presented a simplified elastic solution to analyse the stress and deformation of multi-layered filament-wound composite pipes under internal pressure. The thermomechanical loading of thick-walled composite pipes was considered by Xia, Kemmochi and Takayanagi (2001), Bakaiyan et al. (2009). Xia, Kemmochi and Takayanagi (2001) analysed the filament-wound sandwich pipe and Bakaiyan et al. (2009) considered the multi-layered filament-wound composite pipe under internal pressure and 
thermomechanical loading with thermal variation. Guedes (2010) presented an analytical approach to time-dependent stress-strain state calculation in nonlinear viscoelastic multi-layered composite cylinders.

The following sub-section will show how the usage of composite materials can contribute to tackling one of the challenging problems in oil and gas industry.

\section{Thick-walled fibre composite pipe stress and failure analysis}

In oil and gas industry composite coiled tubing is used for different well intervention operations. In this case the main loads the pipe is subjected are bending load (when it is spooled on the drum), and the outer pressure and thermal loading in the well bore. Coiled tube is thick-walled pipe of several kilometres length. Pultrusion, pull winding and pull braiding processes can be used to manufacture the fibre reinforced pipe of such length. Pultrusion process is the cheapest and easiest one, however the resulting product is highly anisotropic. Pull braiding is the most expensive process and also the most difficult from manufacturer point of view. In this paper we will focus on a pipe, produced by the winding process, subjected to outer pressure loading, which is important for well intervention operations and subsea applications. However, in the applications of water depth over $1000 \mathrm{~m}$, normally, the composite pipes include metal layers (such as subsea flexible pipe) to resist the high tensile load and external buckling load. The research on mechanical response of non-metal composite pipe in the offshore applications was published by Bai et al. (2014 a, 2014b). The method presented in the paper can be modified to solve the problem of multi-layered thick-walled fibre reinforced pipes with metal layer under pressure loading.

Let us consider a multilayered fibre reinforced filament-wound composite pipe under outer pressure. The number of layers in the pipe is $N$, inner radius of the pipe is denoted by $r_{0}$ and outer radius by $r_{a}$. The pipe is subjected to the outer pressure $p_{a}$. The radial, hoop and axial coordinates are denoted by $r, \theta$ and $z$ respectively (see Fig. 1).

As we consider the axisymmetric tube, all displacements, strains and stresses are independent of $\theta$. The radial displacements, $r$, are independent on axial displacements, $z$, as well as axial displacements are not depend on the radial ones. Thus, the displacements are:

$$
u_{r}=u_{r}(r), \quad u_{\theta}=u_{\theta}(r, z), \quad u_{z}=u_{z}(z),
$$

where $u_{r}, u_{\theta}$ and $u_{z}$ are radial, hoop and axial displacements respectively.

The strain-displacement relations can be written as (Xia, Takayanagi and Kemmochi 2001)

$$
\varepsilon_{r}^{(k)}=\frac{d u_{r}^{(k)}}{d r}, \quad \varepsilon_{\theta}^{(k)}=\frac{u_{r}^{(k)}}{r}, \quad \varepsilon_{z}^{(k)}=\varepsilon_{0},
$$




$$
\gamma_{z r}^{(k)}=0, \quad \gamma_{\theta r}^{(k)}=0, \quad \gamma_{z \theta}^{(k)}=\gamma_{0} r,
$$

where $\gamma_{0}$ is a twist of the pipe per unit length and $\varepsilon_{0}$ is constant.

The elastic constitutive equations in the global cylindrical coordinates $(z, \theta, r)$ for the orthotropic layer $k$ can be written as (Xia, Takayanagi and Kemmochi 2001):

$$
\left[\begin{array}{l}
\sigma_{z} \\
\sigma_{\theta} \\
\sigma_{r} \\
\tau_{\theta r} \\
\tau_{z r} \\
\tau_{z \theta}
\end{array}\right]^{(k)}=\left[\begin{array}{llllll}
\bar{C}_{11} & \bar{C}_{12} & \bar{C}_{13} & 0 & 0 & \bar{C}_{16} \\
\bar{C}_{12} & \bar{C}_{22} & \bar{C}_{23} & 0 & 0 & \bar{C}_{26} \\
\bar{C}_{13} & \bar{C}_{23} & \bar{C}_{33} & 0 & 0 & \bar{C}_{36} \\
0 & 0 & 0 & \bar{C}_{44} & \bar{C}_{45} & 0 \\
0 & 0 & 0 & \bar{C}_{45} & \bar{C}_{55} & 0 \\
\bar{C}_{16} & \bar{C}_{26} & \bar{C}_{36} & 0 & 0 & \bar{C}_{66}
\end{array}\right]^{(k)}\left[\begin{array}{l}
\varepsilon_{z} \\
\varepsilon_{\theta} \\
\varepsilon_{r} \\
\gamma_{\theta r} \\
\gamma_{z r} \\
\gamma_{z \theta}
\end{array}\right]^{(k)}
$$

Each layer of the pipe is a unidirectional long fibre composite. If we define 1 as the principal axis along the fibre, and 2 and 3 as transverse directions, the principal stiffness matrix can be written in terms of engineering constants as:

$$
\left[\begin{array}{lll}
C_{11} & C_{12} & C_{13} \\
C_{12} & C_{22} & C_{23} \\
C_{13} & C_{23} & C_{33}
\end{array}\right]=\left[\begin{array}{ccc}
\frac{1}{E_{1}} & -\frac{v_{12}}{E_{1}} & -\frac{v_{12}}{E_{1}} \\
-\frac{v_{12}}{E_{1}} & \frac{1}{E_{2}} & -\frac{v_{23}}{E_{2}} \\
-\frac{v_{12}}{E_{1}} & -\frac{v_{23}}{E_{2}} & \frac{1}{E_{2}}
\end{array}\right]^{-1}
$$

Using the stiffness transformation matrix $\left[A_{k l}\right]$ (see Appendix 1) the off-axis stiffness constants can be calculated from stiffness constants along principal material directions as follows (Xia, Takayanagi and Kemmochi 2001):

$$
\left\{\bar{C}_{i j}^{(k)}\right\}=\left[A_{k l}\right]\left\{C_{i j}^{(k)}\right\}
$$

where

$$
\begin{gathered}
\left\{\bar{C}_{i j}^{(k)}\right\}=\left\{\bar{C}_{11}^{(k)}, \bar{C}_{12}^{(k)}, \bar{C}_{13}^{(k)}, \bar{C}_{16}^{(k)}, \bar{C}_{22}^{(k)}, \bar{C}_{23}^{(k)}, \bar{C}_{26}^{(k)}, \bar{C}_{33}^{(k)}, \bar{C}_{36}^{(k)}, \bar{C}_{44}^{(k)}, \bar{C}_{45}^{(k)}, \bar{C}_{55}^{(k)}, \bar{C}_{66}^{(k)}\right\}^{T}, \\
\left\{C_{i j}^{(k)}\right\}=\left\{C_{11}^{(k)}, C_{22}^{(k)}, C_{33}^{(k)}, C_{12}^{(k)}, C_{13}^{(k)}, C_{23}^{(k)}, G_{23}^{(k)}, G_{12}^{(k)}, G_{13}^{(k)}\right\}^{T} .
\end{gathered}
$$

The equilibrium equations in cylindrical coordinates for a long axisymmetric tube under prescribed loading have the following form (Xia, Takayanagi and Kemmochi 2001; Herakovich 1998):

$$
\begin{gathered}
\frac{d \sigma_{r}^{(k)}}{d r}+\frac{\sigma_{r}^{(k)}-\sigma_{\theta}^{(k)}}{r}=0, \\
\frac{d \tau_{\theta r}^{(k)}}{d r}+\frac{2 \tau_{\theta r}^{(k)}}{r}=0, \\
\frac{d \tau_{z r}^{(k)}}{d r}+\frac{\tau_{z r}^{(k)}}{r}=0 .
\end{gathered}
$$


Integration of the last two equations gives the shear stresses as (Xia, Takayanagi and Kemmochi 2001; Herakovich 1998):

$$
\tau_{\theta r}^{(k)}=\frac{U^{(k)}}{r^{2}}, \quad \tau_{z r}^{(k)}=\frac{W^{(k)}}{r},
$$

where $U^{(k)}$ and $W^{(k)}$ are unknown constants of integration.

After combining the first equilibrium equation (7) with the elastic constitutive equations (3), the straindisplacement relations (2) and the displacement field (1) we obtain the second-order ordinary differential equation (Xia, Takayanagi and Kemmochi 2001) the solution of which can be written as follows:

$$
u_{r}^{(k)}=A^{(k)} r^{\beta(k)}+B^{(k)} r^{-\beta(k)}+\alpha_{1}^{(k)} \varepsilon_{0} r+\alpha_{2}^{(k)} \gamma_{0} r^{2}
$$

where

$$
\beta^{(k)}=\sqrt{\frac{\bar{C}_{22}^{(k)}}{\bar{C}_{33}^{(k)}}}, \quad \alpha_{1}^{(k)}=\frac{\bar{C}_{12}^{(k)}-\bar{C}_{13}^{(k)}}{\bar{C}_{33}^{(k)}-\bar{C}_{22}^{(k)}}, \quad \alpha_{2}^{(k)}=\frac{\bar{C}_{26}^{(k)}-2 \bar{C}_{36}^{(k)}}{4 \bar{C}_{33}^{(k)}-\bar{C}_{22}^{(k)}} .
$$

For the isotropic or transversely-isotropic layers the solution is expressed as (Herakovich 1998):

$$
u_{r}^{(k)}=A^{(k)} r+B^{(k)} r^{-1}
$$

The boundary conditions for the laminated tube subjected to outer pressure are (Xia, Takayanagi and Kemmochi 2001):

$$
\begin{gathered}
\sigma_{r}^{(1)}\left(r_{0}\right)=0, \sigma_{r}^{(N)}\left(r_{a}\right)=-p_{a}, \\
\tau_{\theta r}^{(1)}\left(r_{0}\right)=\tau_{z r}^{(1)}\left(r_{0}\right)=0, \tau_{\theta r}^{(N)}\left(r_{0}\right)=\tau_{z r}^{(N)}\left(r_{0}\right)=0 .
\end{gathered}
$$

From the traction continuity between the layers follows that the two interlaminate shear stresses $\left(\tau_{\theta r}\right.$ and $\left.\tau_{z r}\right)$ were continuous from layer to layer. For a long laminated tube subjected to axisymmetric uniform loading along its length they are zeros. As the layers are perfectly bonded, all displacements must also be continuous from layer to layer. Consequently, the continuity conditions for the considered problem are (Xia, Takayanagi and Kemmochi 2001):

$$
\begin{gathered}
U^{(k)}=W^{(k)}=0, \quad k=\overline{1, N}, \\
\tau_{\theta r}^{(k)}\left(r_{0}\right)=\tau_{z r}^{(k)}\left(r_{0}\right)=0, \quad k=\overline{1, N}, \\
u_{r}^{(k)}\left(r_{k}\right)=u_{r}^{(k+1)}\left(r_{k}\right), \sigma_{r}^{(k)}\left(r_{k}\right)=\sigma_{r}^{(k+1)}\left(r_{k}\right), \quad k=\overline{1, N-1 .}
\end{gathered}
$$

The axial force at the end of the tube is determined by integrating the axial stress over the area of cross section. For the $\mathrm{N}$-layered tube with axial force equal to zero the expression has the form:

$$
2 \pi \sum_{k=1}^{N} \int_{r_{k-1}}^{r_{k}} \sigma_{z}^{(k)}(r) r d r=0
$$


Similarly one can determine the torque, by integrating the moment of the shear stress $\tau_{z \theta}$ over the crosssectional area of the tube. In the considered problem the torque is equal to zero, consequently the expression is written as follows (Xia, Takayanagi and Kemmochi 2001):

$$
2 \pi \sum_{k=1}^{N} \int_{r_{k-1}}^{r_{k}} \tau_{z \theta}^{(k)}(r) r^{2} d r=0
$$

From the strain-displacement relations (2) and the expression for displacements (11) the layer strains can be determined as:

$$
\begin{gathered}
\varepsilon_{r}^{(k)}=\beta(k) A^{(k)} r^{\beta(k)-1}-\beta(k) B^{(k)} r^{-\beta(k)-1}+\alpha_{1}^{(k)} \varepsilon_{0}+2 \alpha_{2}^{(k)} \gamma_{0} r, \\
\varepsilon_{\theta}^{(k)}=A^{(k)} r^{\beta(k)-1}-B^{(k)} r^{-\beta(k)-1}+\alpha_{1}^{(k)} \varepsilon_{0}+\alpha_{2}^{(k)} \gamma_{0} r, \\
\varepsilon_{z}^{(k)}=\varepsilon_{0} \quad \gamma_{\theta r}^{(k)}=0 \quad \gamma_{r z}^{(k)}=0 \quad \gamma_{z \theta}^{(k)}=\gamma_{0} r .
\end{gathered}
$$

The expressions for layer stresses are obtained from constitutive equation (3) and layer strains:

$$
\begin{aligned}
& \tau_{\theta r}^{(k)}=\tau_{r z}^{(k)}=0 \\
& \tau_{z \theta}^{(k)}=\left[\bar{C}_{16}^{(k)}+\left(\bar{C}_{26}^{(k)}+\bar{C}_{36}^{(k)}\right) \alpha_{1}^{(k)}\right] \varepsilon_{0}+\left[\bar{C}_{66}^{(k)}+\left(\bar{C}_{26}^{(k)}+2 \bar{C}_{36}^{(k)}\right) \alpha_{2}^{(k)}\right] \gamma_{0} r \\
& +\left(\bar{C}_{26}^{(k)}+\beta(k) \bar{C}_{36}^{(k)}\right) A^{(k)} r^{\beta(k)-1}+\left(\bar{C}_{26}^{(k)}-\beta(k) \bar{C}_{36}^{(k)}\right) B^{(k)} r^{-\beta(k)-1}, \\
& \sigma_{z}^{(k)}=\left[\bar{C}_{11}^{(k)}+\left(\bar{C}_{13}^{(k)}+\bar{C}_{12}^{(k)}\right) \alpha_{1}^{(k)}\right] \varepsilon_{0}+\left[\bar{C}_{16}^{(k)}+\left(\bar{C}_{12}^{(k)}+2 \bar{C}_{13}^{(k)}\right) \alpha_{2}^{(k)}\right] \gamma_{0} r \\
& +\left(\bar{C}_{12}^{(k)}+\beta(k) \bar{C}_{13}^{(k)}\right) A^{(k)} r^{\beta(k)-1}+\left(\bar{C}_{12}^{(k)}-\beta(k) \bar{C}_{13}^{(k)}\right) B^{(k)} r^{-\beta(k)-1}, \\
& \sigma_{\theta}^{(k)}=\left[\bar{C}_{12}^{(k)}+\left(\bar{C}_{22}^{(k)}+\bar{C}_{23}^{(k)}\right) \alpha_{1}^{(k)}\right] \varepsilon_{0}+\left[\bar{C}_{26}^{(k)}+\left(\bar{C}_{22}^{(k)}+2 \bar{C}_{23}^{(k)}\right) \alpha_{2}^{(k)}\right] \gamma_{0} r \\
& +\left(\bar{C}_{22}^{(k)}+\beta(k) \bar{C}_{23}^{(k)}\right) A^{(k)} r^{\beta(k)-1}+\left(\bar{C}_{22}^{(k)}-\beta(k) \bar{C}_{23}^{(k)}\right) B^{(k)} r^{-\beta(k)-1}, \\
& \sigma_{r}^{(k)}=\left[\bar{C}_{13}^{(k)}+\left(\bar{C}_{23}^{(k)}+\bar{C}_{33}^{(k)}\right) \alpha_{1}^{(k)}\right] \varepsilon_{0}+\left[\bar{C}_{36}^{(k)}+\left(\bar{C}_{23}^{(k)}+2 \bar{C}_{33}^{(k)}\right) \alpha_{2}^{(k)}\right] \gamma_{0} r \\
& +\left(\bar{C}_{23}^{(k)}+\beta(k) \bar{C}_{33}^{(k)}\right) A^{(k)} r^{\beta(k)-1}+\left(\bar{C}_{23}^{(k)}-\beta(k) \bar{C}_{33}^{(k)}\right) B^{(k)} r^{-\beta(k)-1} .
\end{aligned}
$$

Substituting layer stresses (21) into boundary conditions (14) we obtain:

$$
\begin{gathered}
0=\left[\bar{C}_{13}^{(1)}+\left(\bar{C}_{23}^{(1)}+\bar{C}_{33}^{(1)}\right) \alpha_{1}^{(1)}\right] \varepsilon_{0}+\left[\bar{C}_{36}^{(1)}+\left(\bar{C}_{23}^{(1)}+2 \bar{C}_{33}^{(1)}\right) \alpha_{2}^{(1)}\right] \gamma_{0} r_{0} \\
+\left(\bar{C}_{23}^{(1)}+\beta(k) \bar{C}_{33}^{(1)}\right) A^{(1)} r_{0}^{\beta(1)-1}+\left(\bar{C}_{23}^{(1)}-\beta(k) \bar{C}_{33}^{(1)}\right) B^{(1)} r_{0}^{-\beta(1)-1}, \\
-p_{a}=\left[\bar{C}_{13}^{(N)}+\left(\bar{C}_{23}^{(N)}+\bar{C}_{33}^{(N)}\right) \alpha_{1}^{(N)}\right] \varepsilon_{0}+\left[\bar{C}_{36}^{(N)}+\left(\bar{C}_{23}^{(N)}+2 \bar{C}_{33}^{(N)}\right) \alpha_{2}^{(N)}\right] \gamma_{0} r_{a} \\
+\left(\bar{C}_{23}^{(N)}+\beta(k) \bar{C}_{33}^{(N)}\right) A^{(N)} r_{a}^{\beta(N)-1}+\left(\bar{C}_{23}^{(N)}-\beta(k) \bar{C}_{33}^{(N)}\right) B^{(N)} r_{a}^{-\beta(N)-1} .
\end{gathered}
$$


After substitution of the expression for displacement (11) and layer stresses (21) into continuity conditions (17) we obtain for $k=\overline{1, N-1}$ :

$$
\begin{aligned}
A^{(k)} r_{r}^{\beta(k)}+ & B^{(k)} r_{k}{ }^{-\beta(k)}+\alpha_{1}^{(k)} \varepsilon_{0} r_{k}+\alpha_{2}^{(k)} \gamma_{0} r_{k}{ }^{2}=A^{(k+1)} r_{r}^{\beta(k+1)}+B^{(k+1)} r_{k}{ }^{\beta(k+1)}+\alpha_{1}^{(k+1)} \varepsilon_{0} r_{k}+\alpha_{2}^{(k+1)} \gamma_{0} r_{k}{ }^{2} \\
& {\left[\bar{C}_{13}^{(k)}+\left(\bar{C}_{23}^{(k)}+\bar{C}_{33}^{(k)}\right) \alpha_{1}^{(k)}\right] \varepsilon_{0}+\left[\bar{C}_{36}^{(k)}+\left(\bar{C}_{23}^{(k)}+2 \bar{C}_{33}^{(k)}\right) \alpha_{2}^{(k)}\right] \gamma_{0} r_{k} } \\
& +\left(\bar{C}_{23}^{(k)}+\beta(k) \bar{C}_{33}^{(k)}\right) A^{(k)} r_{k}^{\beta(k)-1}+\left(\bar{C}_{23}^{(k)}+\beta(k) \bar{C}_{33}^{(k)}\right) B^{(k)} r_{k}^{-\beta(k)-1}= \\
& {\left[\bar{C}_{13}^{(k+1)}+\left(\bar{C}_{23}^{(k+1)}+\bar{C}_{33}^{(k+1)}\right) \alpha_{1}^{(k+1)}\right] \varepsilon_{0}+\left[\bar{C}_{36}^{(k+1)}+\left(\bar{C}_{23}^{(k+1)}+2 \bar{C}_{33}^{(k+1)}\right) \alpha_{2}^{(k+1)}\right] \gamma_{0} r_{k} } \\
& +\left(\bar{C}_{23}^{(k+1)}+\beta(k+1) \bar{C}_{33}^{(k+1)}\right) A^{(k)} r_{k}^{\beta(k)-1}+\left(\bar{C}_{23}^{(k)}+\beta(k+1) \bar{C}_{33}^{(k+1)}\right) B^{(k+1)} r_{k}^{-\beta(k+1)-1}
\end{aligned}
$$

The expressions for the axial force and torque after layer stresses substitution have the following form:

$$
\begin{aligned}
& 2 \pi \sum_{k=1}^{N} \int_{r_{k-1}}^{r_{k}}\left\{\left[\bar{C}_{11}^{(k)}+\left(\bar{C}_{13}^{(k)}+\bar{C}_{12}^{(k)}\right) \alpha_{1}^{(k)}\right] \varepsilon_{0}+\left[\bar{C}_{16}^{(k)}+\left(\bar{C}_{12}^{(k)}+2 \bar{C}_{13}^{(k)}\right) \alpha_{2}^{(k)}\right] \gamma_{0} r\right. \\
& \left.+\left(\bar{C}_{12}^{(k)}+\beta(k) \bar{C}_{13}^{(k)}\right) A^{(k)} r^{\beta(k)-1}+\left(\bar{C}_{12}^{(k)}+\beta(k) \bar{C}_{13}^{(k)}\right) B^{(k)} r^{-\beta(k)-1}\right\} d r=0, \\
& 2 \pi \sum_{k=1}^{N} \int_{r_{k-1}}^{r_{k}}\left\{\left[\bar{C}_{11}^{(k)}+\left(\bar{C}_{13}^{(k)}+\bar{C}_{12}^{(k)}\right) \alpha_{1}^{(k)}\right] \varepsilon_{0}+\left[\bar{C}_{16}^{(k)}+\left(\bar{C}_{12}^{(k)}+2 \bar{C}_{13}^{(k)}\right) \alpha_{2}^{(k)}\right] \gamma_{0} r\right. \\
& \left.+\left(\bar{C}_{12}^{(k)}+\beta(k) \bar{C}_{13}^{(k)}\right) A^{(k)} r^{\beta(k)-1}+\left(\bar{C}_{12}^{(k)}+\beta(k) \bar{C}_{13}^{(k)}\right) B^{(k)} r^{-\beta(k)-1}\right\} d r=\pi r_{0}^{2} p_{0} .
\end{aligned}
$$

Consequently we derive the following system of equations solving which the stress in the pipe can be obtained:

$\left.\begin{array}{l}\begin{array}{l}\text { Boundary conditions } \\ \text { Continuity conditions } \\ \text { Axial force } \\ \text { Torque }\end{array}\end{array}\right\} \quad X F=Z$

where $X, F$ and $Z$ are given in Appendix 2 .

To calculate failure the stress in pipe are transformed into stresses in principal material directions:

$$
\left[\begin{array}{l}
\sigma_{1} \\
\sigma_{2} \\
\sigma_{3}
\end{array}\right]=\left[\begin{array}{ccc}
m^{2} & n^{2} & 2 m n \\
n^{2} & m^{2} & -2 m n \\
-m n & m n & m^{2}-n^{2}
\end{array}\right]\left[\begin{array}{c}
\sigma_{z} \\
\sigma_{\theta} \\
\tau_{z \theta}
\end{array}\right]
$$

where $m=\cos \theta, n=\sin \theta$ ( $\theta$ is the angle between the pipe axis and filament).

A comprehensive analysis of failure criteria for composite materials was given in the World Wide Failure Exercise (Hinton et al. 2004), where their advantages, drawbacks and the applicability issues were considered in detail. In this study, for the failure prediction we use the Tsai-Hill failure criterion introducing some appropriate modifications to this criterion found in literature.

The Tsai-Hill failure coefficient ( FC ) has the form 


$$
F C=\frac{\sigma_{1}^{2}}{X_{T}^{2}}-\frac{\sigma_{1} \sigma_{2}}{X_{T}^{2}}+\frac{\sigma_{2}^{2}}{Y_{T}^{2}}+\frac{\tau_{12}^{2}}{S^{2}}
$$

where $X_{T}$ and $Y_{T}$ are longitudinal and transverse tensile strength respectively and $S$ is shear strength.

It is generally recognized that Tsai-Hill failure criterion underestimates the failure stress because the transverse tensile strength of a unidirectional lamina is generally much less than its transverse compressive strength and the compressive strengths are not used in the Tsai-Hill failure theory. The modified form of Tsai-Hill failure criterion was formulated by Kawai and Saito (2009). For off-axis tensile loading it agrees with the original formulae, however it takes a modified form for off-axis compressive loading:

$$
\begin{aligned}
& F C=\frac{\sigma_{1}^{2}}{X_{T}^{2}}-\frac{\sigma_{1} \sigma_{2}}{X_{T}^{2}}+\frac{\sigma_{2}^{2}}{Y_{T}^{2}}+\frac{\tau_{12}^{2}}{S^{2}}, \quad \text { if } \sigma_{2}>0 ; \\
& F C=\frac{\sigma_{1}^{2}}{X_{C}^{2}}-\frac{\sigma_{1} \sigma_{2}}{X_{C}^{2}}+\frac{\sigma_{2}^{2}}{Y_{C}^{2}}+\frac{\tau_{12}^{2}}{\left(S-\mu_{L} \sigma_{2}\right)^{2}}, \text { if } \sigma_{2}<0,
\end{aligned}
$$

where $\mu_{L}$ is a material constant that characterizes the in-plane shear strength differential (SD) effect.

According to the criterion the failure occurs when the failure coefficient becomes greater than 1 . The criterion can be expressed as follows:

$$
\begin{aligned}
& F C<1 \Rightarrow \text { no failure } \\
& F C \geq 1 \Rightarrow \text { failure }
\end{aligned}
$$

\section{Numerical results and discussion}

As a numerical example the pipes of different designs made of carbon/epoxy fibre composite (T300/LY5052) subjected to outer pressure are considered. Taking the outer pressure into account is particularly important for well intervention operations and subsea applications. The properties of the composite are given in Table 1.

The comparison of stress distribution through the wall thickness in the pipes of different designs subjected to the outer pressure of 30MPa is given below (Figures 2, 3). The pipes have $3 \mathrm{~cm}$ outer diameter and $2 \mathrm{~cm}$ inner diameter.

First we compared the stress distribution in the pipes of following designs: $[60,-60,60,-60,0]$ and $[60,-60,0]$. In both designs the inner layers have properties of opposite fibre orientations $(60,-60)$ and outer layer is unidirectional layer of $0^{0}$ fibre orientation. The difference in designs is the thickness of the outer $0^{0}$ fibre layer. We are interested in the influence of the $0^{0}$ fibre layer thickness on the stress distribution in the pipe. The biggest jump in axial and hoop stresses for both designs is between $0^{0}$ fibre layer and $(60,-60)$ inner layers (Figure 2). However it is not true for shear stress where the jump in stresses between $60^{\circ}$ an $-60^{\circ}$ layers is nearly twice higher than between $0^{\circ}$ fibre layer and (60,- 
60) layers. For the pipe with thicker $0^{0}$ outer fibre layer the axial stress in outer layer is lower, then for the pipe with thinner $0^{0}$ outer fibre layer. However the axial stresses in $(60,-60)$ layers are slightly higher. For hoop stresses the difference in stress distribution in inner layers is more significant. It can reach $100 \mathrm{MPa}$ at some points of the inner diameter. The hoop and shear stresses in outer $0^{0}$ fibre layer for both designs are the same.

The comparison of the stress distribution in the pipes with inner layer of $0^{0}$ fibre angle is shown in Figure 3 . The considered pipe lay-ups are $[0,60,-60,60,-60]$ and $[0,60,-60]$. Here we compare the stress distributions when the outer layers of the pipe have opposite fibre orientations and inner layers are $0^{0}$ fibre layers of different thicknesses. For these designs the biggest jump in axial and hoop stresses is (as well as in previous case) between $0^{0}$ fibre layer and (60,-60) layers. For hoop stresses this jump is lower than the jump in stresses between $60^{\circ}$ and $-60^{0}$ layers. For axial stress in $0^{0}$ fibre layer we have the similar to previous case picture, axial stress in thicker layer is lower than in thinner layer. However the magnitude of the axial stresses is lower when $0^{0}$ fibre layer is inner layer. The same is true for hoop, radial and shear stresses. For example, if we compare the maximum absolute magnitude of radial stress for pipes with outer and inner $0^{0}$ fibre layer, we can see that for a pipe with $0^{0}$ inner fibre layer it is twice lower.

To predict the failure the Tsai-Hill failure criterion and the modified Tsai-Hill failure criterion are used. The failure occurs when the failure coefficient, equations (26) and (27), is equal to 1, consequently, there is no failure when the failure coefficient is lower than 1 . The difference between Tsai-Hill failure criterion coefficient and modified TsaiHill failure criterion coefficient (with $\mu_{L}=0.7$, Kawai and Saito 2009) is shown in Figures 4, 5 for the pipe with layup $[0, \alpha,-\alpha, 0]$ subjected to different pressure. We can see that the higher the pressure, the higher the difference between failure coefficients.

Variations of the modified Tsai-Hill failure criterion coefficient depending on the winding angle are shown in Figures 6-12. The results are presented for different stuck sequences and pressure loads. Figure 6 demonstrates that for the pipe design with outer $0^{0}$ fibre layer and inner layers of opposite fibre orientation the angles which allow the pipe to withstand outer pressure of 30MPa vary from $25^{\circ}$ to $90^{\circ}$. If for the same pipe design the working pressure is two times higher, the suitable winding angles would be from $43^{0}$ to $90^{0}$ (see Figure 7). For the pipe with [ $\left.\alpha,-\alpha, 0\right]$ lay-up subjected to outer pressure the failure coefficient is higher on the outer radius than on the inner radius for the range of winding angles between $35^{\circ}$ to $90^{\circ}$ (Figures 6 and 7) and lower for the range between $0^{0}$ to $35^{0}$. The difference between failure coefficients on the inner and the outer radii is high when the winding angles range between $0^{0}$ to $10^{\circ}$. For the winding angles in the range from $70^{\circ}$ to $90^{\circ}$, the failure coefficients on the outer and the inner radii are nearly constant and the difference between them is much lower than for winding angles close to $0^{0}$. 
In Figures 8 and 9 the modified Tsai-Hill failure criterion coefficient variation with the winding angle and outer pressure is considered for the pipe design with inner and outer $0^{0}$ fibre layers and middle layers of opposite fibre orientation. The suitable winding angles vary from $45^{\circ}$ to $90^{\circ}$ for $60 \mathrm{MPa}$ outer pressure and from $58^{0}$ to $90^{\circ}$ for $80 \mathrm{MPa}$.

Figures 10-12 give a more detailed through the thickness variation of failure criterion coefficient as a function of winding angle. The suitable winding angles for pipe with inner $0^{0}$ fibre layer and outer layers of opposite fibre orientation vary from around $45^{0}$ to $90^{\circ}$ for $60 \mathrm{MPa}$ outer pressure (Figure 10). A small jump in failure coefficient distribution occurs on the interface of $0^{\circ}$ and $\alpha$ fibre layers.

Figure 11 shows that if we add outer layer of $90^{\circ}$ fibre orientation, the pipe will be able to withstand the outer pressure of 60MPa. However the failure coefficient distribution will not be as smooth, having more jumps. In Figure 12 the distribution for $[\alpha,-\alpha]$ lay-up is presented. This pipe design gives a very smooth distribution of failure criterion coefficient, however not all winding angles are suitable to withstand outer pressure. The winding angles which allow the pipe withstand 60MPa outer pressure are vary from around $45^{\circ}$ to $90^{\circ}$.

For the winding angles close to $0^{0}$ the failure coefficient smoothly decreases from the inner to the outer pipe radius for $[\alpha,-\alpha]$ lay-up (Figure 12). For pipe with $[0, \alpha,-\alpha]$ lay-up the failure coefficient decreases with the small jump between $0^{0}$ and $\alpha$ fibre layers from the inner to the outer pipe radius for the winding angles close to $0^{0}$ (Figure 10). However, for the pipe with $[0, \alpha,-\alpha, 90]$ lay-up the failure coefficient for the winding angles close to $0^{0}$ decreases from the inner to the outer radius in the $0^{0}, \alpha$ and $-\alpha$ layers and increases in the outer $90^{\circ}$ fibre layer (Figure 11). For the winding angles close to $90^{\circ}$ the failure coefficient increases from the inner to the outer pipe radius for all three considered cases (Figure 10-12).

Through the thickness variations of failure criterion coefficient for a range of outer pressures (30MPa - 80MPa) are shown in Figures 13-16 for different lay-ups. The pipe with [0,30,-30,30,-30,0] lay-up can withstand outer pressure no more than $30 \mathrm{MPa}$ (Figure 13). However for the pipe with only outer layer of $0^{0}$ fibre orientation (Figure 14) the maximum outer pressure increases to $35 \mathrm{MPa}$.

Figures 15 and 16 show that if we change the winding angle in previous designs from $30^{\circ}$ to $60^{\circ}$, the pipe will be able to withstand the outer pressure up to $80 \mathrm{MPa}$.

\section{Conclusions}

The paper presents a review of the application of composite materials in oil and gas industry. In particular the potential use of different types of composite materials (such as GFRP, PMC, syntactic foams etc.) in the industry is considered. 
Special attention is paid to long fibre reinforced pipes, focusing on thin and thick walled filament-wound pipes under different types of loading.

As an example of modelling composite pipes, the problem of thick-walled multi-layered filament-wound pipe subjected to outer pressure was solved analytically. Taking the outer pressure into account is particularly important for well intervention operations and subsea applications. Stress and failure analysis was performed for the pipes with different lay-ups subjected to outer pressure of various magnitudes.

The method presented in this paper can be adopted in the future for modelling multi-layered thick-walled pipes with metal layers. The latter would be important for the deep-water offshore applications (such as subsea flexible pipes) since for the installations of water depth over $1000 \mathrm{~m}$, the composite pipes usually include metal layers to resist the high tensile load and external buckling load.

\section{Acknowledgements}

Financial support of the part of this research by The Royal Society, The Royal Academy of Engineering, and The Carnegie Trust for the Universities of Scotland is gratefully acknowledged. 


\section{References}

Ajit KR. 1991. Response of thick laminated composite rings to thermal stresses. Composite Structures. 18: 125-138.

Ansari R, Alisafaei F, Ghaedi P. 2010. Dynamic analysis of multi-layered filament-wound composite pipes subjected to cyclic internal pressure and cyclic temperature. Composite Structures. 92: 1100-1109.

Alexander C. 2007. Development of a composite repair system for reinforcing offshore risers. Ph.D. Texas A\&M University.

Bai Y, Xu W, Cheng P, Wang N, Ruan W. 2014. Behaviour of reinforced thermoplastic pipe (RTP) under combined external pressure and tension. Ships and Offshore Structures. 9(4): 464-474.

Bai Y, Ruan W, Cheng P, Yu B, Xu W. 2014. Buckling of reinforced thermoplastic pipe (RTP) under combined bending and tension. Ships and Offshore Structures. 9(5): 525-539.

Bakaiyan H, Hosseini H, Ameri E. 2009. Analysis of multi-layered filament-wound composite pipes under combined internal pressure and thermomechanical loading with thermal variations. Composite Structures. 88: 532-541.

Bouchonneau N, Sauvant-Moynot V, Choqueuse D, Grosjean F, Poncet E, Perreux D. 2010. Experimental testing and modelling of an industrial insulated pipeline for deep sea application. Journal of Petroleum Science and Engineering. 73: $1-12$.

Bouchonneau N, Sauvant-Moynot V, Grosjean F, Choqueuse D, Poncet E, Perreux D. 2007. Thermal insulation material for subsea pipelines: benefits of instrumented full scale testing to predict the long term thermo-mechanical behavior. Proceedings of the Offshore Technology Conference - OTC 18679, Houston, Texas, USA.

Bouhafs M, Sereir Z, Chateauneuf A. 2012. Probabilistic analysis of the mechanical responce of thick composite pipes under internal pressure. International Journal of Pressure Vessels and Piping. 95: 7-15.

Choqueuse D, Chomard A, Bucherie C. 2002. Insulation materials for ultra deep seaflow assurance: evaluation of the material properties. Proceedings of the Offshore Technology Conference - OTC 14115, Houston, Texas, USA.

Chouchaoui CS, Ochoa OO. 1999. Similitude study for laminated cylindrical tube under tension, torsion, bending, internal \& external pressure. Part I: Governing equations and Part II: Scale models. Composite Structures. 44(4): 221236. 
d'Almeida JRM, de Almeida RC, de Lima WR. 2008. Effect of water absorption of the machanical behavior of fiberglass pipes used for offshore service water. Composite Structures. 83: 221-225.

Davies P, Carlsson LA. 2009. Delamination of composite cylinders. Major Accomplishments in Composite Materials and Sandwich Structures. I: 67-82.

Davies P, Riou L, Mazeas F, Warnier P. 2005. Thermoplastic composite cylinders for underwater applications. Journal of Thermoplastic Composite Materials. 18(5): 417-443.

Deniz M, Karakuzu R. 2012. Seawater effect on impact behaviour of glass-epoxy composite pipes. Composites: Part B. 43: $1130-1138$.

Deniz M, Ozdemir O, Ozen M, Karakuzu R. 2013. Failure pressure and impact response of glass-epoxy pipes exposed to seawater. Composites: Part B. 53: 355-361.

Fine T, Sautereau H, Sauvant-Moynot V. 2003. Innovative processing and mechanical properties of high temperature syntactic foams based on a thermoplastic/thermoset matrix. Journal of Materials Science. 38: 2709-2716.

Friedrich R. 1999. Composite Materials for Offshore Operations-2 (CMOO-2). In: Wang SS, Williams JG, Lo KH, editors. American Bureau of Shipping, Houston, TX; p. 183-196.

Gibson AG. 2000. Composite materials in the offshore industry. Comprehensive Composite Materials. 6: 459-478.

Grant TS, Bradley WL. 1995. In situ observations in SEM of degradation of graphite/epoxy composite materials due to seawater immersion. Journal of Composite Materials. 29(7): 852-867.

Grosjean F, Bouchonneau N, Choqueuse D, Sauvant-Moynot V. 2009. Comprehensive analyses of syntactic foam behaviour in deepwater environment. Journal of Materials Science. 44(6): 1462-1468.

Gu H. 2009. Behaviours of glass/fiber unsaturated polyester composites under seawater environment. Materials \& Design. 30(4): 1337-1340.

Gu H. 2009. Dynamic mechanical analysis of the seawater treated glass/polyester composites. Materials \& Design. 30(7): 2774-2777.

Guedes RM. 2010. Nonlinear viscoelastic analysis of thick-walled cylindrical composite pipes. International Journal of Mechanical Sciences. 52: 1064-1073. 
Guz IA. 1998. Composites with interlaminar imperfections: Substantiation of the bounds for failure parameters in compression, Composites Part B. 29(4): 343-350.

Guz IA, Herrmann KP. 2003. On the lower bounds for critical loads under large deformations in non-linear hyperelastic composites with imperfect interlaminar adhesion, European Journal of Mechanics, A/Solids. 22(6): 837-849.

Guz IA, Rodger AA, Guz AN, Rushchitsky JJ. 2008. Predicting the properties of micro and nanocomposites: From the microwhiskers to bristled nano-centipedes, The Philosophical Transactions of the Royal Society A. 366(1871): 18271833.

Guz IA, Rushchitsky JJ. 2004. Theoretical description of a debonding mechanism in fibrous micro- and nanocomposites. International Applied Mechanics. 40(10): 1129-1136.

Hale JM, Gibson AG. 1998. Coupon tests of fibre reinforced plastics at elevated temperatures in offshore processing environments. Journal of Composite Materials. 32(6): 526-543.

Hale JM, Gibson AG, Speake SD. 2002. Biaxial failure envelope and creep testing of fibre reinforced plastic pipes in high temperature aqueous environments. Journal of Composite Materials. 36: 257- 270.

Herakovich CT. 1998. Mechanics of fibrous composites. John Wiley and Sons, Inc.

Hinton MJ, Kaddour AS, Soden PD, editors. 2004. Failure criteria in fibre reinforced polymer composites: The WorldWide Failure Exercise, Elsevier.

Hull D, Legg MJ, Spencer B. 1978. Failure of glass/polyester filament wound pipe. Composites. 9: 17-24.

Kashtalyan M. 2004. Three-dimensional elasticity solution for bending of functionally graded rectangular plates. European Journal of Mechanics A/Solids. 23: 853-864.

Kashtalyan M, Menshykova M. 2009. Three-dimensional elasticity solution for sandwich panels with a functionally graded core. Composite Structures. 87: 36-43.

Kawai M, Saito S. 2009. Off-axis strength differential effects in unidirectional carbon/epoxy laminates at different strain rates and predictions of associated failure envelopes. Composites:Part A. 40: 1632-1649.

Kochetkov VA, Maksimov RD. 1996. Water absorption and swelling of glass/epoxy syntactic foams. Mechanics of Composite Materials. 32: 61-70. 
Lekhnitskii SG. 1981. Theory of elasticity of an anisotropic body. Moskow: MIR Publishers

Mally TS, Johnston AL, Chann M, Walker RH, Keller MW. 2013. Performance of a carbon-fibre/epoxy composite for the underwater repair of pressure equipment. Composite Structures. 100: 542-547.

Menshykova M, Guz IA. 2014. Stress analysis of layered thick-walled composite pipes subjected to bending loading. International Journal of Mechanical Sciences. 88: 289-299.

Menshykova MV, Guz IA, Menshykov OV. 2009. A unified computational approach to instability of periodic laminated materials. CMES - Computer Modeling in Engineering \& Sciences. 51(3): 239-259.

Mistry J, Gibson AG, Wu Y-S. 1992. Failure of composite cylinders under combined external pressure and axial loading. Composite Structures 22: 193-200.

Natsuki T, Takayanagi H, Tsuda H. 2003. Prediction of bending strength for filament-wound composite pipes. Journal of Reinforced Plastics and Composites. 22(8): 695-710.

Ochoa OO, Ross GR. 1998. Hybrid composites: models and tests for environmental aging. Journal of Reinforced Plastics and Composites. 17(9): 787-799.

Ogi K, Takeda N. 1997. Effect of moisture content on nonlinear deformation behavior of CF/epoxy composites. Journal of Composite Materials. 31(6): 530-551.

Pae KD, Rhee KY. 1995. Effects of hydrostatic pressure on the compressive behavior of thick laminated $45^{\circ}$ and $90^{\circ}$ unidirectional graphite-fiber/epoxy-matrix composites. Composites Science and Technology. 53(3): 281-287.

Rhee KY, Ha SR, Park SJ, Kim HJ, Jung DH. 2006. Fracture behavior of seawater-absorbed carbon/epoxy laminated composites in the hydrostatic pressure condition. Materials Science and Engineering A. 419: 209-213.

Rhee KY, Lee SM, Park SJ. 2004. Effect of hydrostatic pressure on the mechanical behavior of seawater-absorbed carbon/epoxy composite. Materials Science and Engineering A. 384: 308-313.

Rhee KY, Pae KD. 1995. Effects of hydrostatic pressure on the compressive properties of laminated, $0^{0}$ unidirectional, graphite fiber/epoxy matrix thick-composite. Journal of Composite Materials. 29(10): 1295-1307.

Rodriguez DE, Ochoa OO. 2004. Flexural response of spoolable composite tubulars: an integrated experimental and computational assessment. Composite Science and Technology. 64(13-14): 2075-2088. 
Rosenow MWK. 1984. Wind angle effects in glass fiber-reinforced polyester filament wound pipes. Composites. 15: 144-52.

Russell AJ, Street KN. 1989. Moisture and temperature effects on the Mode I and Mode II interlaminar fracture of graphite/epoxy composites. Key Engineering Materials. 37: 199-208 .

Sauvant-Moynot V, Duval S, Gimenez N, Kittel J. 2007. Hot wet aging of glass syntactic foam coating monitored by impedance spectroscopy. Progress in Organic Coatings. 59: 179-185.

Sauvant-Moynot V, Gimenez N, Sautereau H. 2006. Hydrolytic ageing of syntactic foams for thermal insulation in deep water: degradation mechanisms and water uptake model. Journal of Materials Science. 41(13): 4047-4054.

Shamsuddoha M, Islam MM, Aravinthan T, Manalo A, Lau K. 2013. Effectiveness of using fibre-reinforced polymer composites for underwater steel pipeline repairs. Composite Structures. 100: 40-54.

Shin ES, Pae KD. 1992a. Effects of hydrostatic pressure on in-plane shear properties of graphite/epoxy composites. Journal of Composite Materials. 26(6): 828-868.

Shin ES, Pae KD. 1992b. Effects of hydrostatic pressure on the torsional shear behavior of graphite/epoxy composites. Journal of Composite Materials. 26(4): 462-485.

Sloan FE, Seymour RJ. 1992. The effect of seawater exposure on mode I interlaminar fracture and crack growth in graphite epoxy. Journal of Composite Materials. 26(18): 2655-2673.

Soden PD, Kitching R, Tse PC. 1989. Experimental failure stresses for $\pm 55^{0}$ filament wound glass fiber reinforced plastic tubes under biaxial loads. Composites. 20: 125-35.

Song B, Chen W, Yanagita T, Frew DJ. 2005. Temperature effects on dynamic compressive behavior of an epoxy syntactic foam. Composite Structures. 67: 289-298.

Soutis C, Guz IA. 2001. Predicting fracture of layered composites caused by internal instability. Composites Part A. 32(9): 1243-1253.

Spencer B, Hull D. 1978. Effect of winding angle on the failure of filament wound pipe. Composites. 9: $263-71$.

Starbuck JM, Eberle C. 2000. Analytical solution for the design of spoolable composite tubing. Third International Conference on Composite Materials for Offshore Operations. Houston, TX, October 31 - November 2. 
Taheri F. 2013. Advanced fiber-reinforced polymer (FRP) composites for the manufacture and rehabilitation of pipes and tanks in the oil and gas industry. In: Bai J, editor. Advanced fiber-reinforced polymer (FRP) composites for structural applications. Woodhead Publishing Limited; p. 662-704.

Togo M, Nakamura T, Takahashi K. 2000. Effects of moisture absorption on the dynamic interlaminar fracture toughness of carbon/epoxy composites. Journal of Composite Materials. 34(8), 630-648.

Uemura M, Fukunaga H. 1981. Probabilistic burst strength of filament wound cylinders under internal pressure. Journal of Composite Materials. 15: 462-480.

Watkins L. 1988. 7th International Conference on Offshore Mechanics and Arctic Engineering, Houston, Texas, USA.

Weitsman YJ. 1998. Effects of Fluids on Polymeric Composites - A Review, University of Tennessee Report MAES98-5.0-CM. August.

Weitsman YJ, Elahi M. 2000. Effects of fluids on the deformation, strength and durability of polymeric composites An overview. Mechanics of Time-Dependent Materials. 4(2): 107-126.

Wild PM, Vickers GW. 1997. Analysis of filament-wound cylindrical shells under combined centrifugal, pressure and axial loading. Composites Part A: Applied Science and Manufacturing. 28(1): 47-55.

Xia M, Takayanagi H, Kemmochi K. 2001. Analysis of multi-layered filament-wound composite pipes under internal pressure. Composite Structures. 53: 483-491.

Xia M, Kemmochi K, Takayanagi H. 2001. Analysis of filament-wound fibre-reinforced sandwich pipe under combined internal pressure and thermomechanical loading. Composite Structures. 51: 273-283.

Xia M, Takayanagi H, Kemmochi K. 2002. Bending behaviour of filament-wound fiber-reinforced sandwich pipes. Composite Structures. 56: 201-210.

Zinoviev PA, Tsvetkov SV, Kulish GG, van den Berg RW, Van Schepdael LJMM. 2001. The behavior of high-strength unidirectional composites under tension with superposed hydrostatic pressure. Composites Science and Technology. 61(8): 1151-1161. 


\section{Appendix 1.}

The stiffness transformation matrix for the coordinate system between the principal material axis and the cylindrical axis [63]:

$$
\left[A_{k l}\right]=\left[\begin{array}{ccccccccc}
m^{4} & n^{4} & 0 & 2 m^{2} n^{2} & 0 & 0 & 0 & 0 & 4 m^{2} n^{2} \\
m^{2} n^{2} & m^{2} n^{2} & 0 & m^{4}+n^{4} & 0 & 0 & 0 & 0 & -4 m^{2} n^{2} \\
0 & 0 & 0 & 0 & m^{2} & n^{2} & 0 & 0 & 0 \\
m^{3} n & -m n^{3} & 0 & -m^{3} n+m n^{3} & 0 & 0 & 0 & 0 & -2 m^{3} n+2 m n^{3} \\
n^{4} & m^{4} & 0 & 2 m^{2} n^{2} & 0 & 0 & 0 & 0 & 4 m^{2} n^{2} \\
0 & 0 & 0 & 0 & n^{2} & m^{2} & 0 & 0 & 0 \\
m n^{3} & -m^{3} n & 0 & m^{3} n-m n^{3} & 0 & 0 & 0 & 0 & 2 m^{3} n-2 m n^{3} \\
0 & 0 & 1 & 0 & 0 & 0 & 0 & 0 & 0 \\
0 & 0 & 0 & 0 & m n & -m n & 0 & 0 & 0 \\
0 & 0 & 0 & 0 & 0 & 0 & m^{2} & n^{2} & 0 \\
0 & 0 & 0 & 0 & 0 & 0 & -m n & m n & 0 \\
0 & 0 & 0 & 0 & 0 & 0 & n^{2} & m^{2} & 0 \\
m^{2} n^{2} & m^{2} n^{2} & 0 & -2 m^{2} n^{2} & 0 & 0 & 0 & 0 & \left(m^{2}-n^{2}\right)^{2}
\end{array}\right]
$$

where $m=\cos \varphi$ and $n=\sin \varphi$ (angle $\varphi$ is the angle between material principal axis along the fibre and cylindrical axial axis).

\section{Appendix 2.}

$$
Z=\left[\begin{array}{l}
-p_{0} \\
0 \\
0 \\
0 \\
0 \\
0 \\
0 \\
-p_{a} \\
0 /\left(r_{0}^{2} p_{0} / 2\right) \\
0
\end{array}\right] X=\left[\begin{array}{l}
X(1) \\
* \\
X(N) \\
X(N+1) \\
\bullet \\
X(2 N) \\
X(2 N+1) \\
X(2 N+2)
\end{array}\right] \begin{aligned}
& X(1)=A^{(1)} \\
& X(N)=A^{(N)} \\
& X(2 N)=B^{(N)} \\
& X(2 N+2)=\varepsilon_{0} \\
&
\end{aligned}
$$




\begin{tabular}{|c|c|c|c|c|c|c|c|c|c|}
\hline$F(1,1)$ & 0 & 0 & 0 & $F(1, N+1)$ & 0 & 0 & 0 & $F(1,2 N+1)$ & $F(1,2 N+2)$ \\
\hline$*$ & $*$ & 0 & 0 & $*$ & $*$ & 0 & 0 & * & * \\
\hline 0 & $F(k, k)$ & $F(k, k+1)$ & 0 & 0 & $F(k, N+k)$ & $F(k, N+k+1)$ & 0 & $F(k, 2 N+1)$ & $F(k, 2 N+2)$ \\
\hline 0 & 0 & $*$ & $*$ & 0 & 0 & $*$ & * & $*$ & $*$ \\
\hline$\circ$ & $\circ$ & 0 & 0 & $\circ$ & $\circ$ & 0 & 0 & $\circ$ & $\circ$ \\
\hline 0 & $F(N+k, k)$ & $F(N+k, k+1)$ & 0 & 0 & $F(N+k, N+k)$ & $F(N+k, N+k+1)$ & 0 & $F(N+k, 2 N+1)$ & $F(N+k, 2 N+2)$ \\
\hline 0 & 0 & $\circ$ & $\circ$ & 0 & 0 & $\circ$ & $\circ$ & $\circ$ & $\circ$ \\
\hline 0 & 0 & 0 & $F(2 N, N)$ & 0 & 0 & 0 & $F(2 N, 2 N)$ & $F(2 N, 2 N+1)$ & $F(2 N, 2 N+2)$ \\
\hline$\bullet$ & $F(2 N+1, k)$ & $\bullet$ & $\bullet$ & $\otimes$ & $F(2 N+1, N+k)$ & $\otimes$ & $\otimes$ & $F(2 N+1,2 N+1)$ & $F(2 N+1,2 N+2)$ \\
\hline$\oplus$ & $F(2 N+2, k)$ & $\oplus$ & $\oplus$ & $x$ & $F(2 N+2, N+k)$ & $x$ & $x$ & $F(2 N+2,2 N+1)$ & $F(2 N+2,2 N+2)$ \\
\hline
\end{tabular}




$$
\begin{aligned}
& k=\overline{1, N-1} \\
& F(1,1)=\left(\bar{C}_{23}^{(1)}+\beta(1) \bar{C}_{33}^{(1)}\right) r_{0}^{\beta(1)-1} \quad F(1, N+1)=\left(\bar{C}_{23}^{(1)}-\beta(1) \bar{C}_{33}^{(1)}\right) r_{0}^{\beta(1)-1} \quad F(1,2 N+1)=\bar{C}_{13}^{(1)}+\left(\bar{C}_{23}^{(1)}+\bar{C}_{33}^{(1)}\right) \alpha_{1}^{(1)} \\
& F(1,2 N+2)=\left[\left(\bar{C}_{23}^{(1)}+2 \bar{C}_{33}^{(1)}\right) \alpha_{2}^{(1)}+\bar{C}_{36}^{(1)}\right] r_{0} \\
& F(k, k)=r_{k}^{\beta(k)} F(k, k+1)=-r_{k}^{\beta(k+1)} \quad F(k, N+k)=r_{k}^{-\beta(k)} \quad F(k, N+k+1)=-r_{k}^{-\beta(k+1)} \quad F(k, 2 N+1)=\left(\alpha_{1}^{(k)}-\alpha_{1}^{(k+1)}\right) r_{k} \\
& F(k, 2 N+2)=\left(\alpha_{2}^{(k)}-\alpha_{2}^{(k+1)}\right) r_{k}^{2} \\
& F(N+k, k)=\left(\bar{C}_{23}^{(k)}+\beta(k) \bar{C}_{33}^{(k)}\right) r_{k}^{\beta(k)-1} \quad F(N+k, k+1)=-\left(\bar{C}_{23}^{(k+1)}+\beta(k+1) \bar{C}_{33}^{(k+1)}\right) r_{k}^{\beta(k+1)-1} \\
& F(N+k, k)=\left(\bar{C}_{23}^{(k)}-\beta(k) \bar{C}_{33}^{(k)}\right) r_{k}^{-\beta(k)-1} \quad F(N+k, k+1)=-\left(\bar{C}_{23}^{(k+1)}-\beta(k+1) \bar{C}_{33}^{(k+1)}\right) r_{k}^{-\beta(k+1)-1} \\
& F(N+k, 2 N+1)=\left(\bar{C}_{13}^{(k)}-\bar{C}_{13}^{(k+1)}\right)+\left(\bar{C}_{23}^{(k)}+\bar{C}_{33}^{(k)}\right) \alpha_{k}^{(k)}-\left(\bar{C}_{23}^{(k+1)}+\bar{C}_{33}^{(k+1)}\right) \alpha_{k}^{(k+1)} \\
& F(N+k, 2 N+2)=\left[\left(\bar{C}_{23}^{(k)}+2 \bar{C}_{33}^{(k)}\right) \alpha_{2}^{(k)}-\left(\bar{C}_{23}^{(k+1)}+2 \bar{C}_{33}^{(k+1)}\right) \alpha_{2}^{(k+1)}+\left(\bar{C}_{36}^{(k)}-\bar{C}_{36}^{(k+1)}\right)\right] r_{k} \\
& F(2 N, 2 N+1)=\bar{C}_{13}^{(N)}+\left(\bar{C}_{23}^{(N)}+\bar{C}_{33}^{(N)}\right) \alpha_{1}^{(N)} \quad F(2 N, 2 N+2)=\left[\left(\bar{C}_{23}^{(N)}+2 \bar{C}_{33}^{(N)}\right) \alpha_{2}^{(N)}+\bar{C}_{36}^{(N)}\right] r_{a} \\
& F(2 N+1,2 N+1)=\sum_{k=1}^{N}\left[\bar{C}_{11}^{(k)}+\left(\bar{C}_{12}^{(k)}+\bar{C}_{13}^{(k)}\right) \alpha_{1}^{(k)}\right] \frac{r_{k}^{2}-r_{k-1}^{2}}{2} \quad F(2 N+1,2 N+2)=\sum_{k=1}^{N}\left[\bar{C}_{16}^{(k)}+\left(\bar{C}_{12}^{(k)}+2 \bar{C}_{13}^{(k)}\right) \alpha_{2}^{(k)}\right] \frac{r_{k}^{3}-r_{k-1}^{3}}{3} \\
& F(2 N+2,2 N+1)=\sum_{k=1}^{N}\left[\bar{C}_{16}^{(k)}+\left(\bar{C}_{26}^{(k)}+\bar{C}_{36}^{(k)}\right) \alpha_{1}^{(k)}\right] \frac{r_{k}^{3}-r_{k-1}^{3}}{3} \quad F(2 N+2,2 N+2)=\sum_{k=1}^{N}\left[\bar{C}_{66}^{(k)}+\left(\bar{C}_{26}^{(k)}+2 \bar{C}_{36}^{(k)}\right) \alpha_{2}^{(k)}\right] \frac{r_{k}^{4}-r_{k-1}^{4}}{4} \\
& k=\overline{1, N} \\
& F(2 N+1, k)=\frac{\bar{C}_{12}^{(k)}+\beta(1) \bar{C}_{13}^{(k)}}{\beta(1)+1}\left(r_{k}^{\beta(1)+1}-r_{k-1}^{\beta(1)+1}\right) \quad F(2 N+1, N+k)=\frac{\bar{C}_{12}^{(k)}+\beta(1) \bar{C}_{13}^{(k)}}{1-\beta(1)}\left(r_{k}^{-\beta(1)+1}-r_{k-1}^{-\beta(1)+1}\right) \\
& F(2 N+2, k)=\frac{\bar{C}_{26}^{(k)}+\beta(1) \bar{C}_{36}^{(k)}}{\beta(1)+2}\left(r_{k}^{\beta(1)+2}-r_{k-1}^{\beta(1)+2}\right) \quad F(2 N+2, N+k)=\frac{\bar{C}_{26}^{(k)}-\beta(1) \bar{C}_{36}^{(k)}}{2-\beta(1)}\left(r_{k}^{-\beta(1)+2}-r_{k-1}^{-\beta(1)+2}\right)
\end{aligned}
$$


Table 1. Properties of carbon/epoxy unidirectional fibre composite (T300/LY5052) [65]

\begin{tabular}{|l|l|}
\hline $\mathrm{E}_{1}(\mathrm{GPa})$ & 135 \\
\hline $\mathrm{E}_{2}(\mathrm{GPa})$ & 8 \\
\hline $\mathrm{G}_{12}(\mathrm{GPa})$ & 3.8 \\
\hline$v_{12}$ & 0.27 \\
\hline$v_{23}$ & 0.49 \\
\hline Longitudinal tensile strength (MPa) & 1860 \\
\hline Transverse tensile strength (MPa) & 76 \\
\hline Longitudinal compressive strength (MPa) & 1470 \\
\hline Transverse compressive strength (MPa) & 85 \\
\hline Shear strength (MPa) & 98 \\
\hline
\end{tabular}




\section{Figure captions.}

Figure 1. Multi-layered filament-wound pipe in cylindrical coordinates (adapted from [64]).

Figure 2. Through the thickness distribution of stresses. Dashed line is for $[60,-60,0]$ and solid line is for $[60,-60,60,-60,0]$ lay-up.

Figure 3. Through the thickness distribution of stresses. Dashed line is for $[0,60,-60]$ and solid line is for $[0,60,-60,60,-$ 60] lay-up.

Figure 4. Difference between Tsai-Hill and modified Tsai-Hill failure criterion coefficients (FC modified-FC) vs winding angle at outer pressure of 60MPa for $[0, \alpha,-\alpha, 0]$ lay-up.

Figure 5. Difference between Tsai-Hill and modified Tsai-Hill failure criterion coefficients (FC modified-FC) vs winding angle at outer pressure of 80MPa for $[0, \alpha,-\alpha, 0]$ lay-up.

Figure 6. Variations of failure criterion coefficient vs winding angle at outer pressure of 30MPa for $[\alpha,-\alpha, 0]$ lay-up.

Figure 7. Variations of failure criterion coefficient vs winding angle at outer pressure of 60MPa for $[\alpha,-\alpha, 0]$ lay-up.

Figure 8. Variations of failure criterion coefficient vs winding angle at outer pressure of 60MPa for $[0, \alpha,-\alpha, 0]$ lay-up.

Figure 9. Variations of failure criterion coefficient vs winding angle at outer pressure of 80MPa for $[0, \alpha,-\alpha, 0]$ lay-up.

Figure 10. Through the thickness variations of failure criterion coefficient for $[0, \alpha,-\alpha]$ lay-up and $60 \mathrm{MPa}$ outer pressure.

Figure 11. Through the thickness variations of failure criterion coefficient for $[0, \alpha,-\alpha, 90]$ lay-up and $60 \mathrm{MPa}$ outer pressure.

Figure 12. Through the thickness variations of failure criterion coefficient for $[\alpha,-\alpha]$ lay-up and 60MPa outer pressure.

Figure 13. Through the thickness distribution of failure criterion coefficient for a range of outer pressures with $[0,30,-30,30,-30,0]$ lay-up.

Figure 14. Through the thickness distribution of failure criterion coefficient for a range of outer pressures with [30,-30,30,-30,0] lay-up.

Figure 15. Through the thickness distribution of failure criterion coefficient for a range of outer pressures with $[0,60,-60,60,-60,0]$ lay-up.

Figure 16. Through the thickness distribution of failure criterion coefficient for a range of outer pressures with [60,-60,60,-60,0] lay-up. 


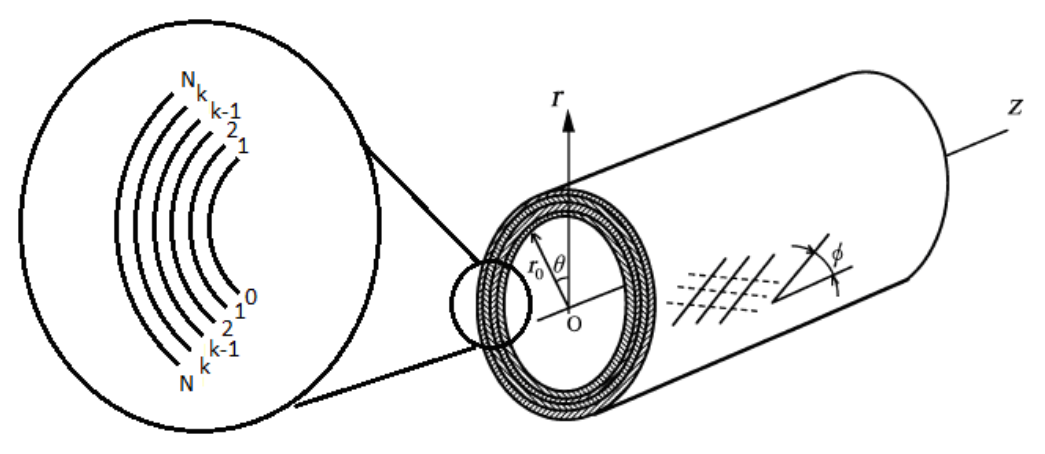

Figure 1. 

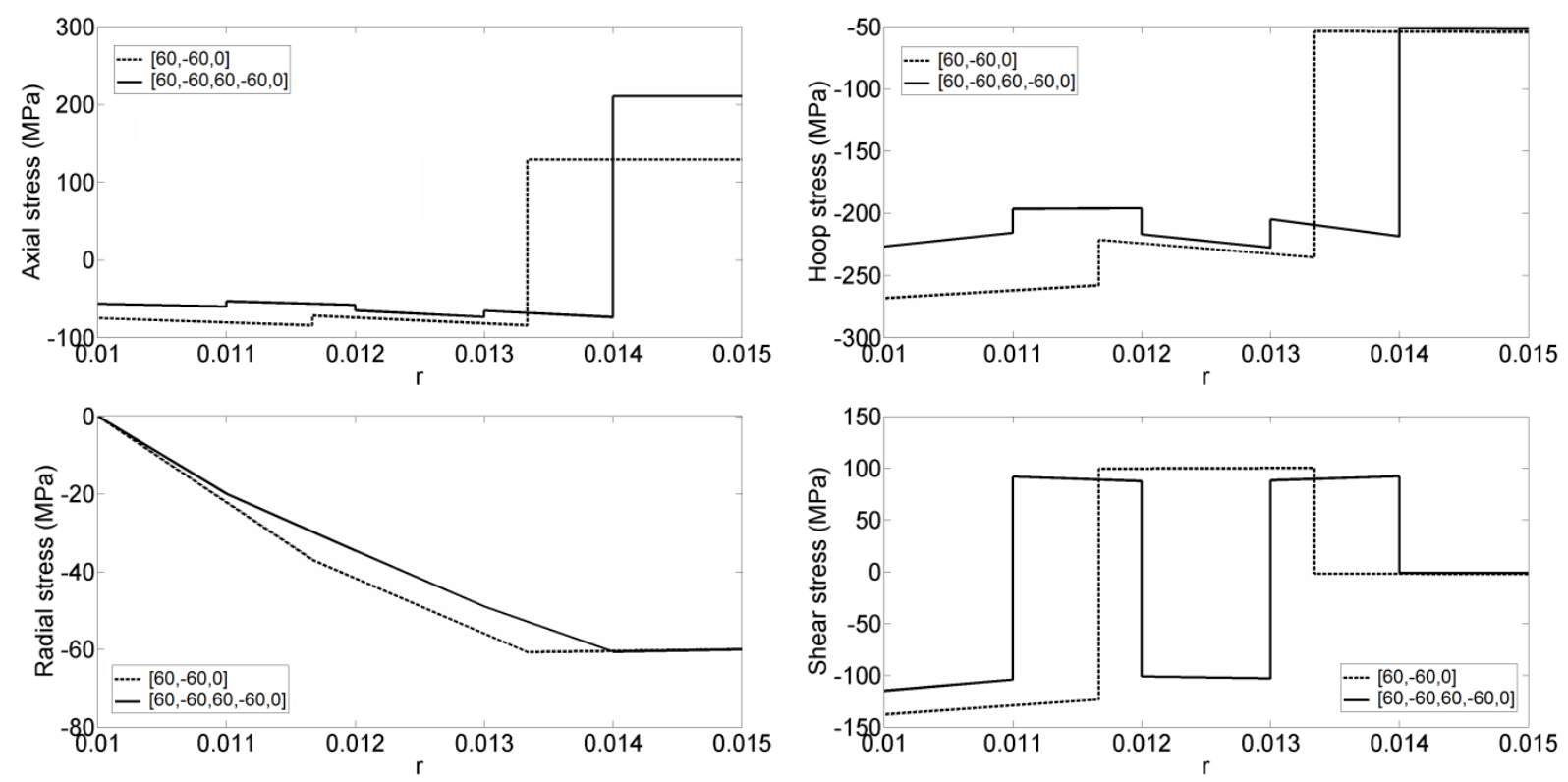

Figure 2.
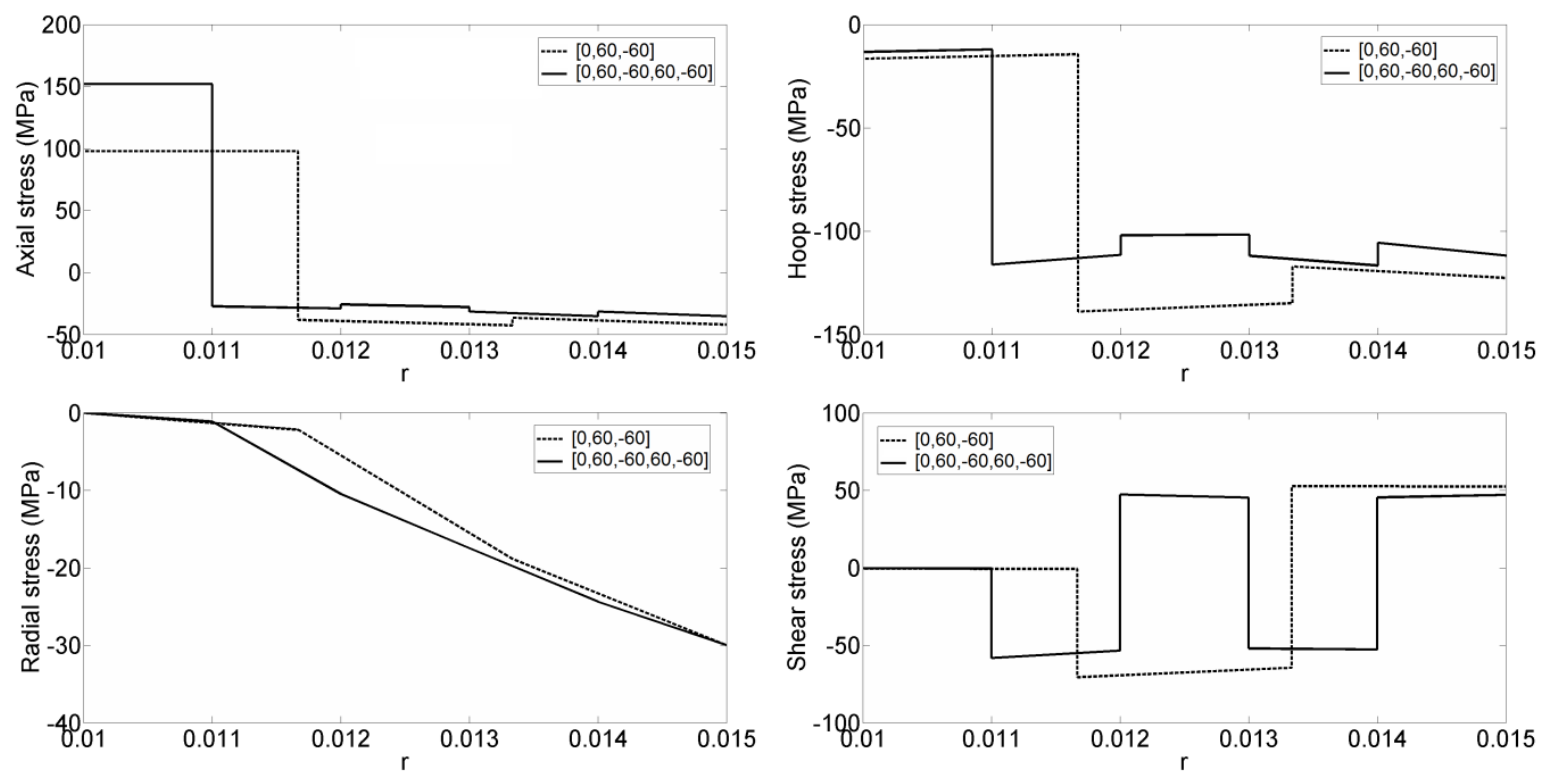

Figure 3. 


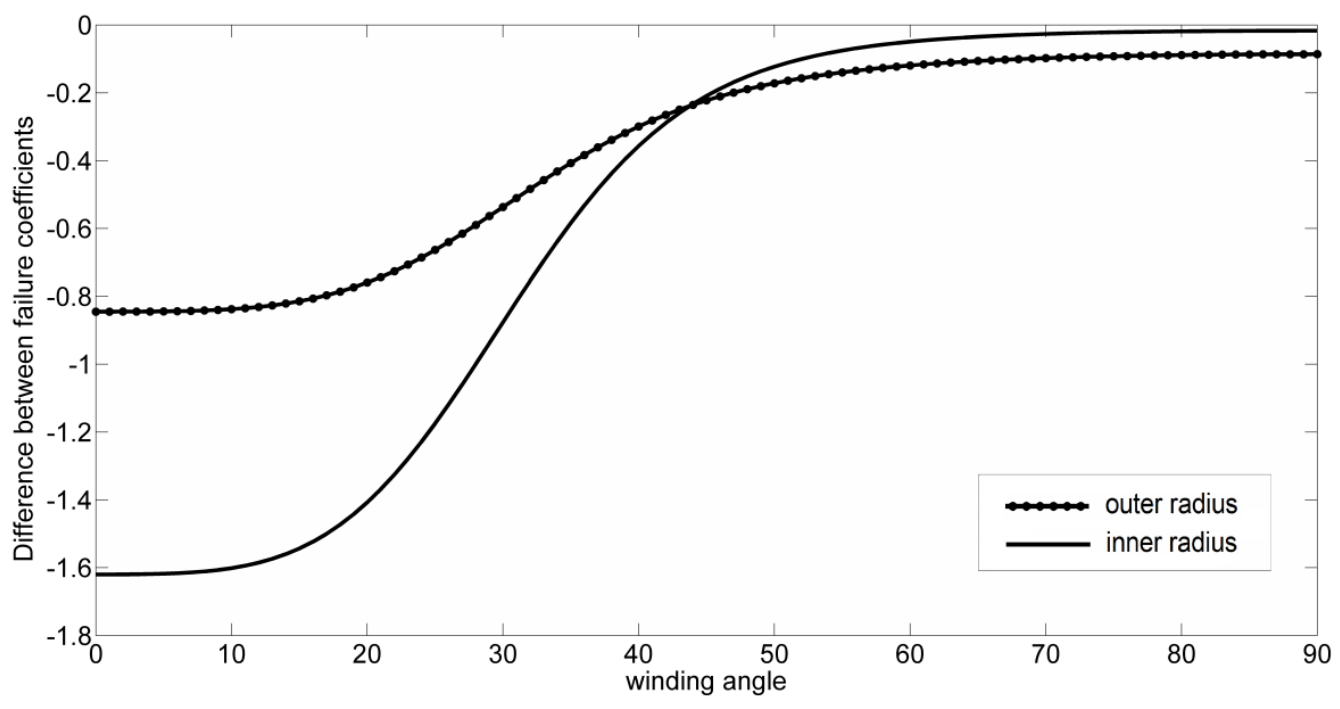

Figure 4.

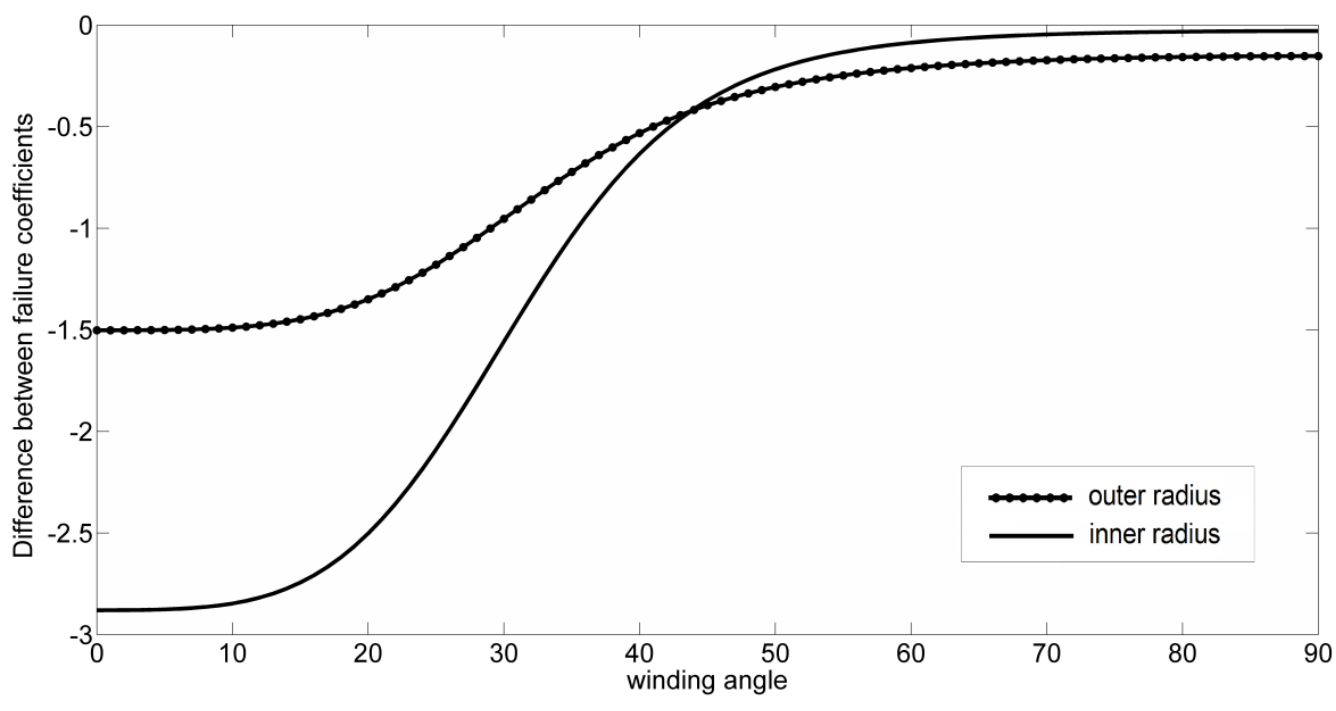

Figure 5. 


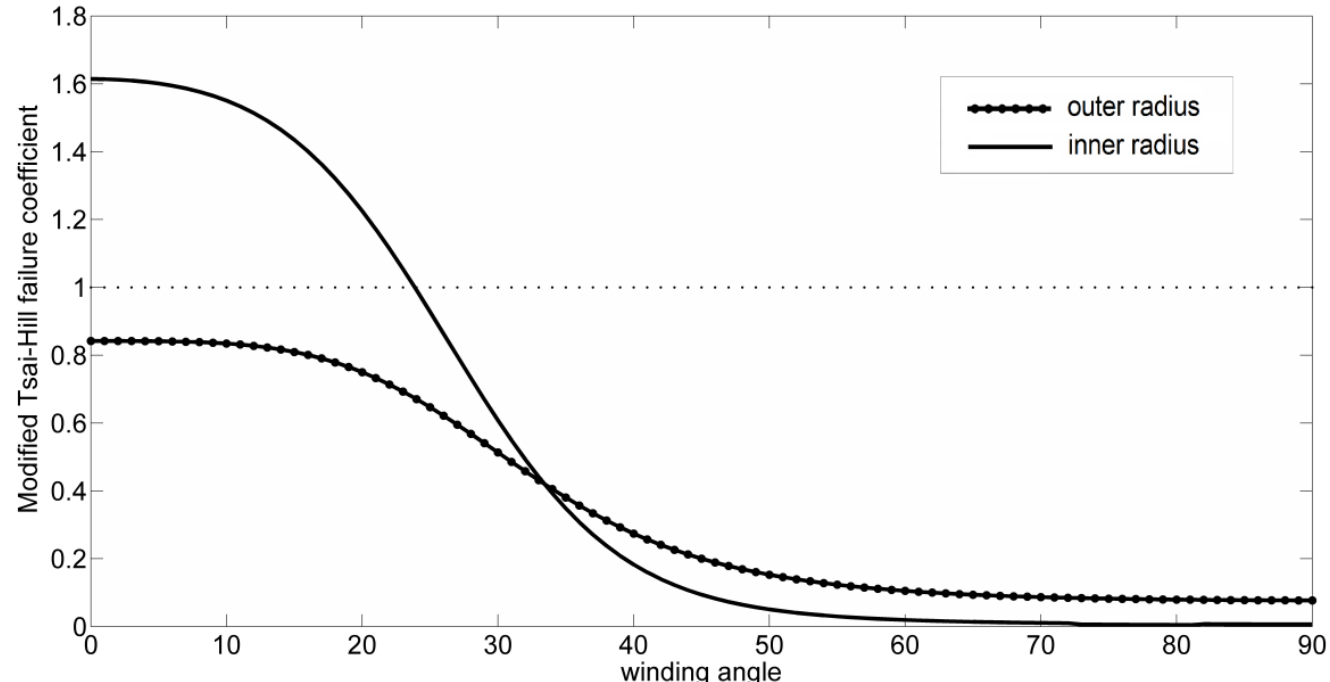

Figure 6.

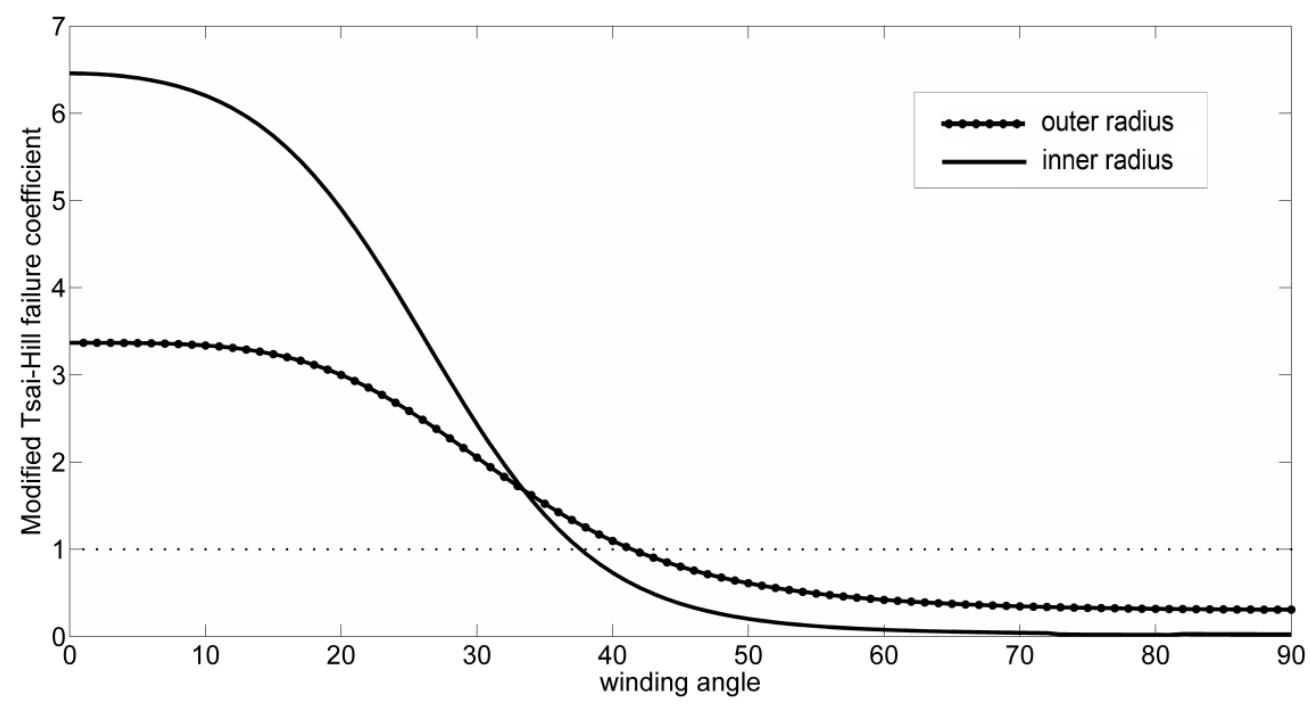

Figure 7. 


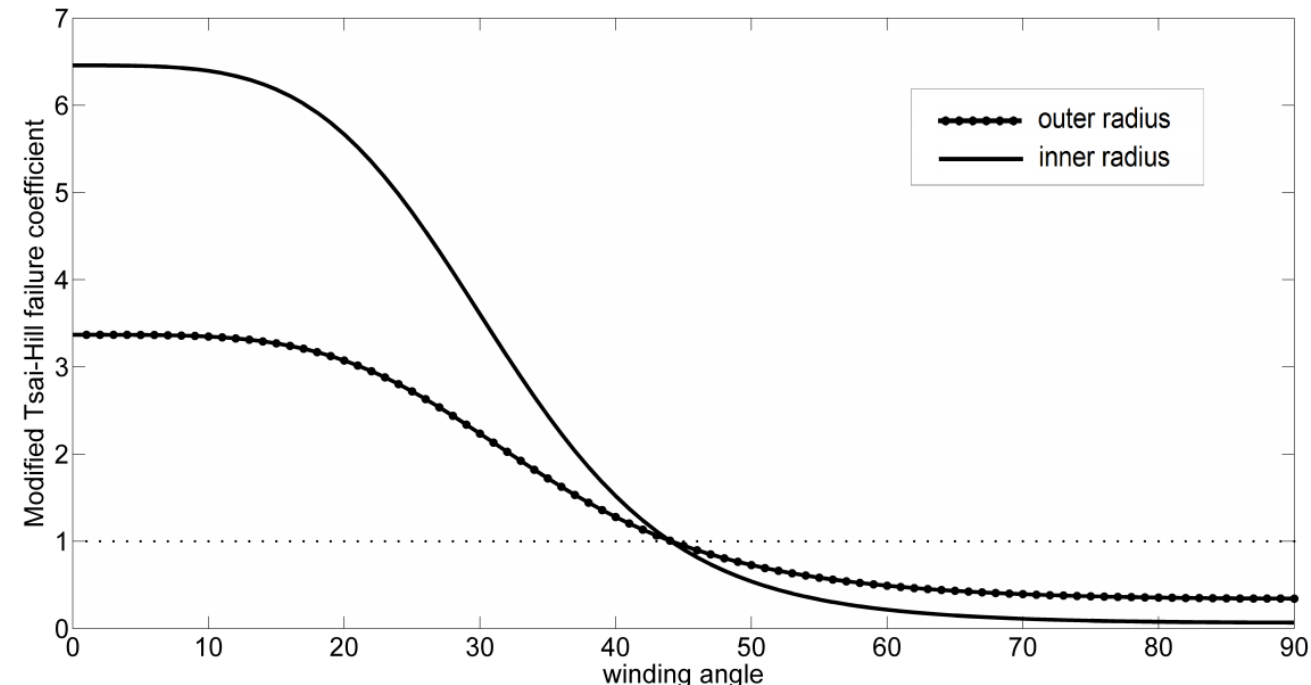

Figure 8.

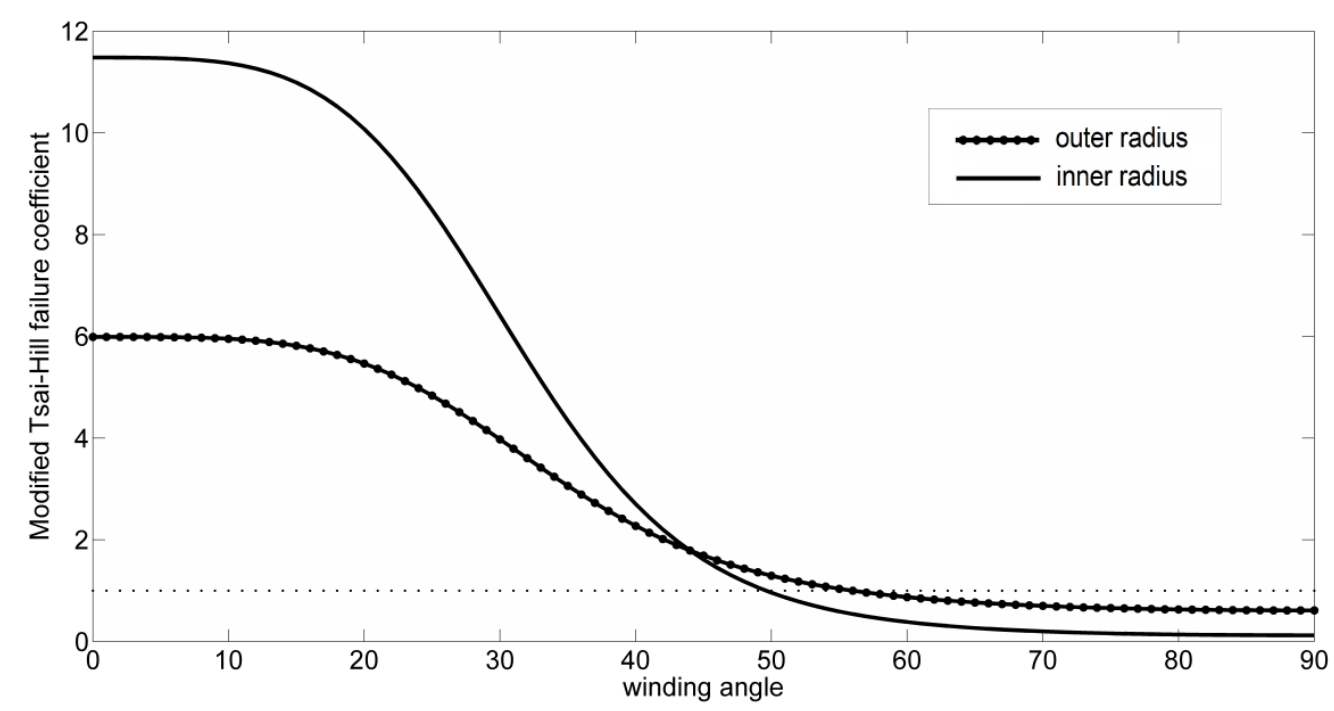

Figure 9. 


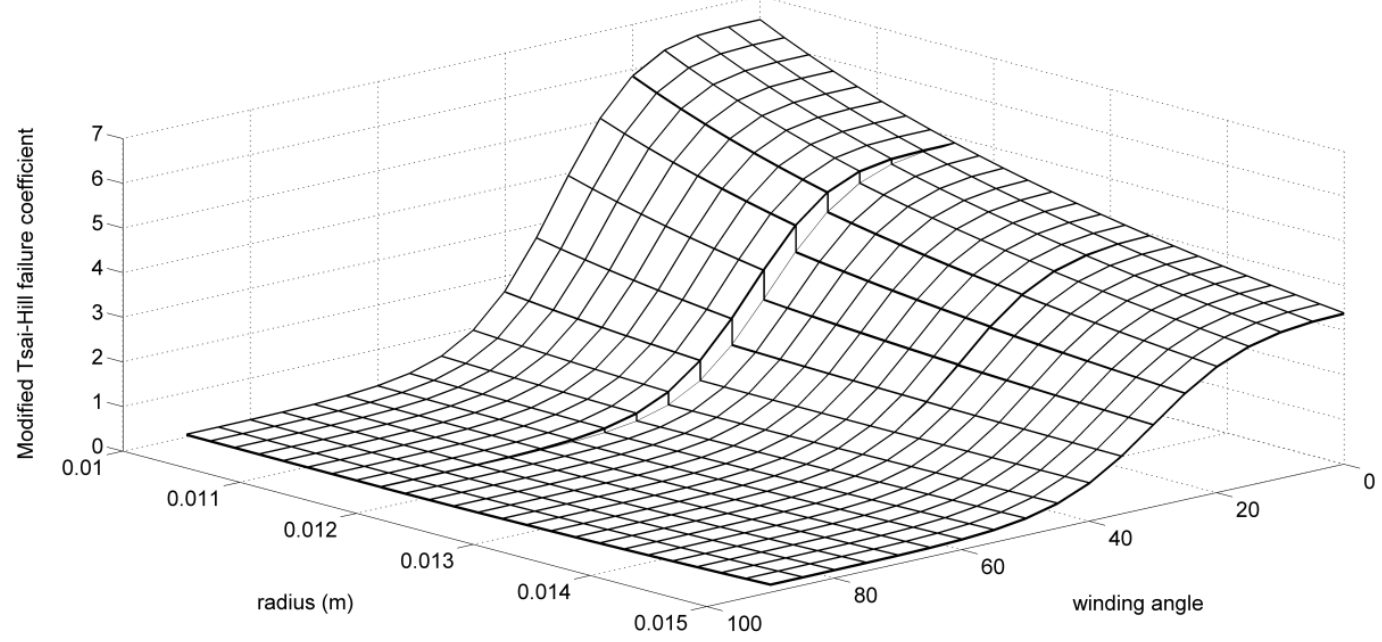

Figure 10.

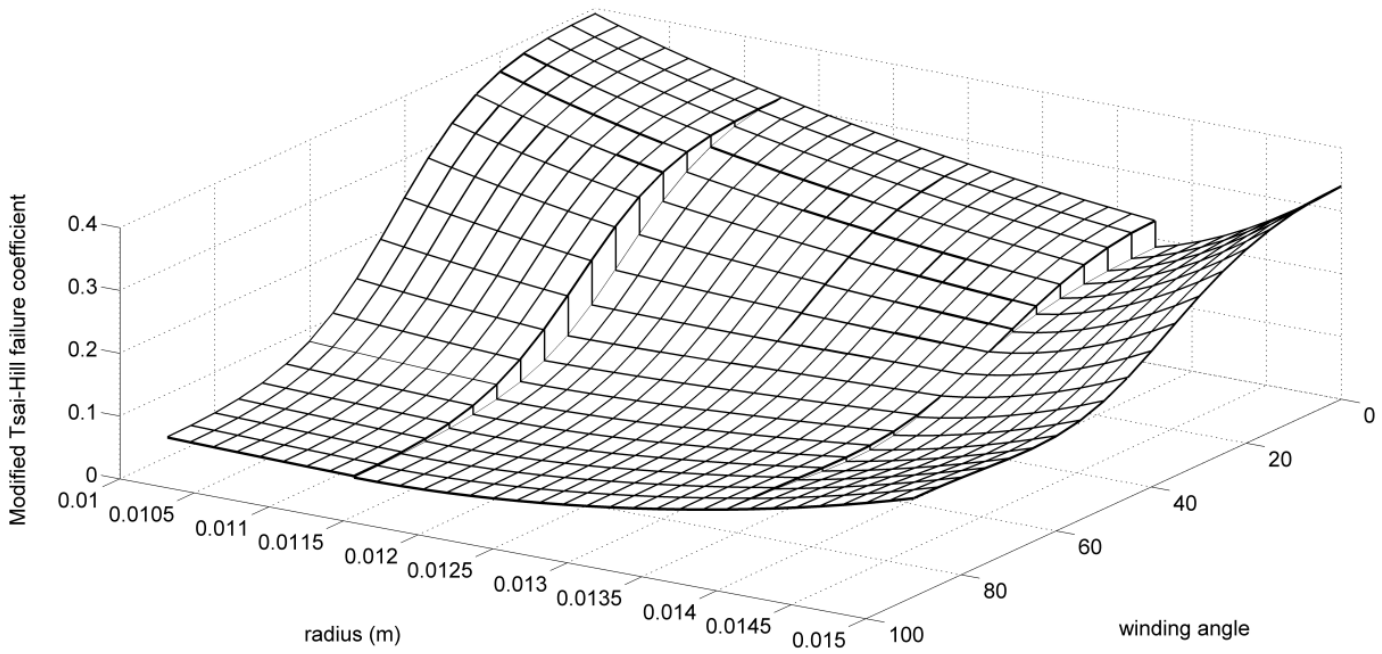

Figure 11. 


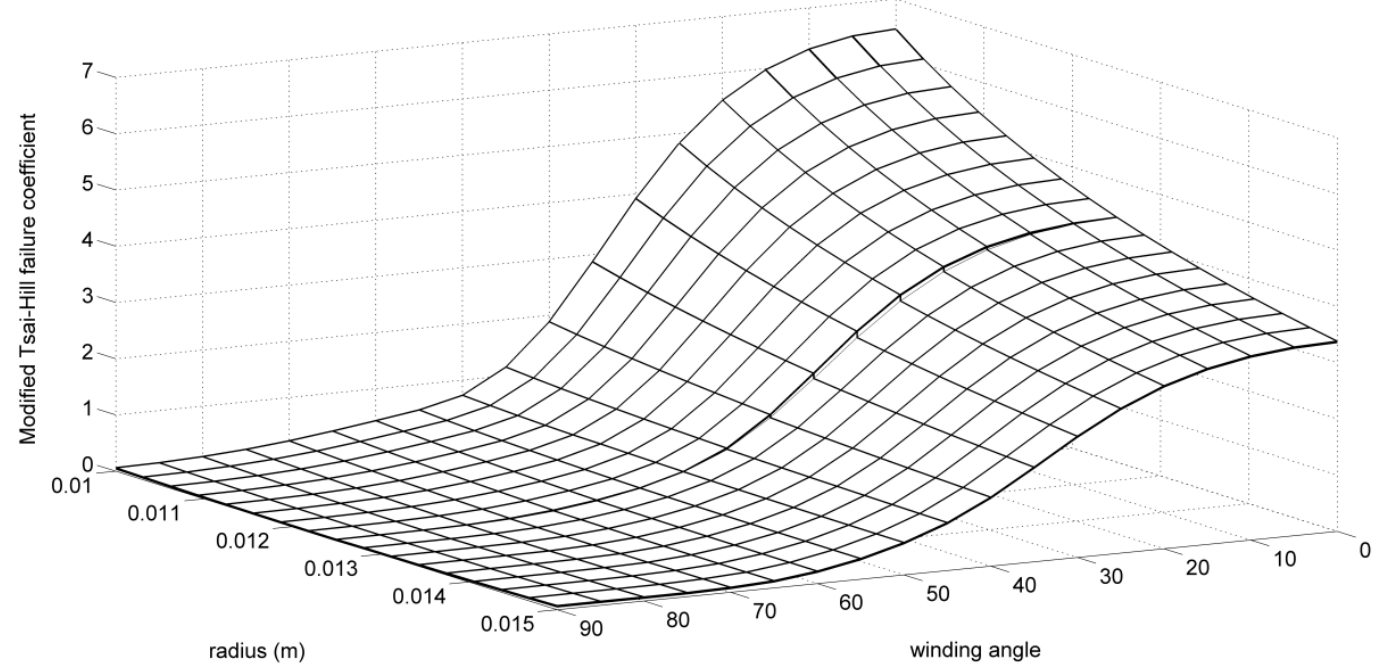

Figure 12.

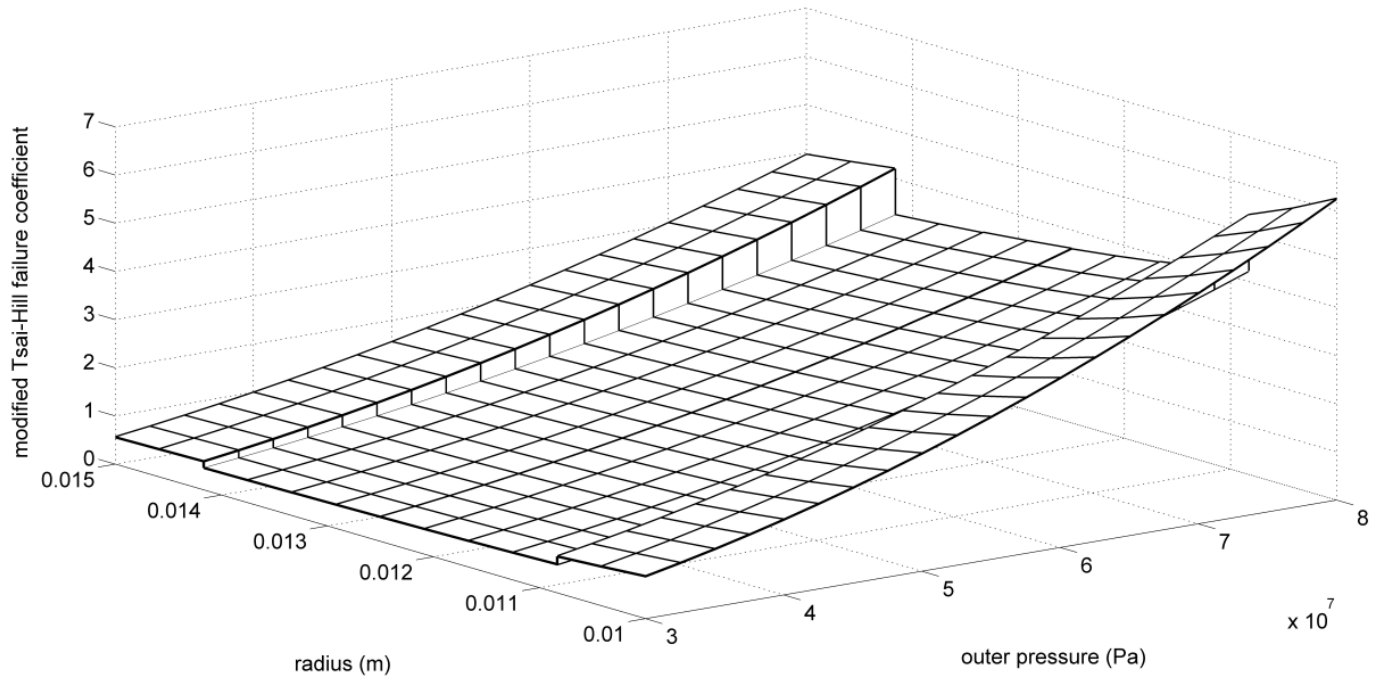

Figure 13. 


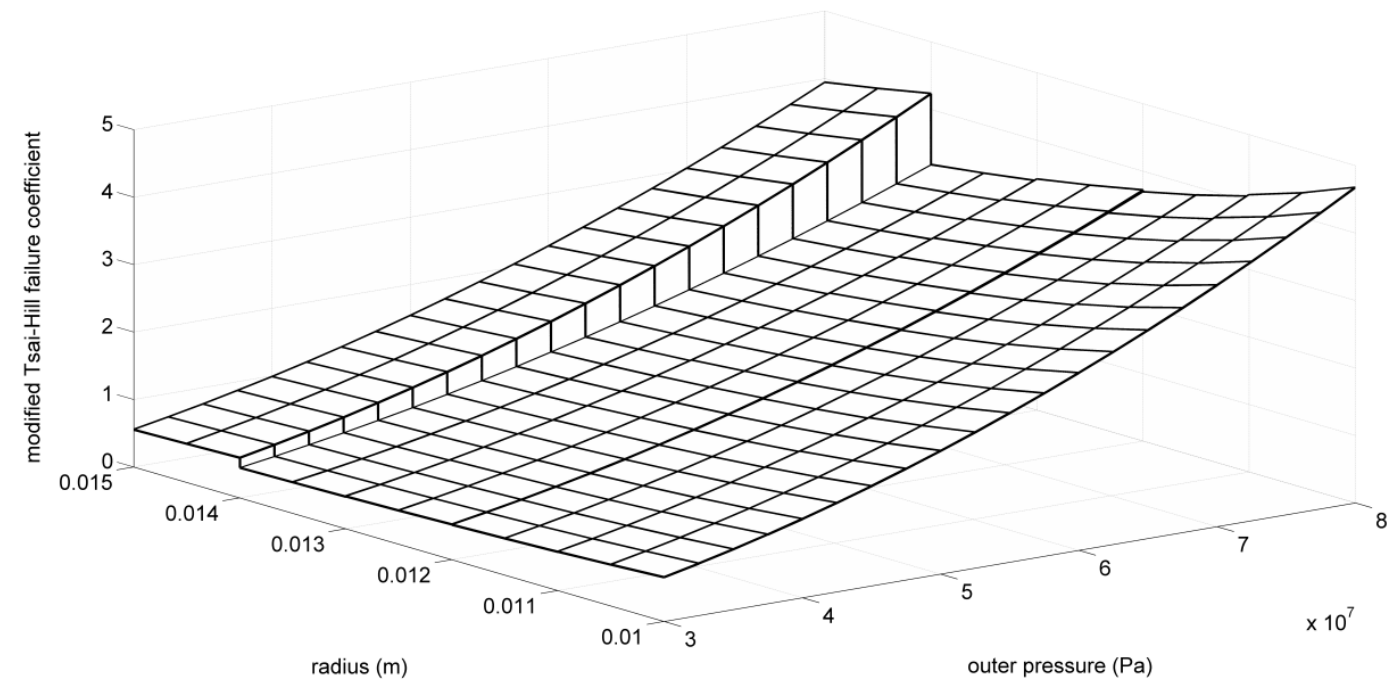

Figure 14.

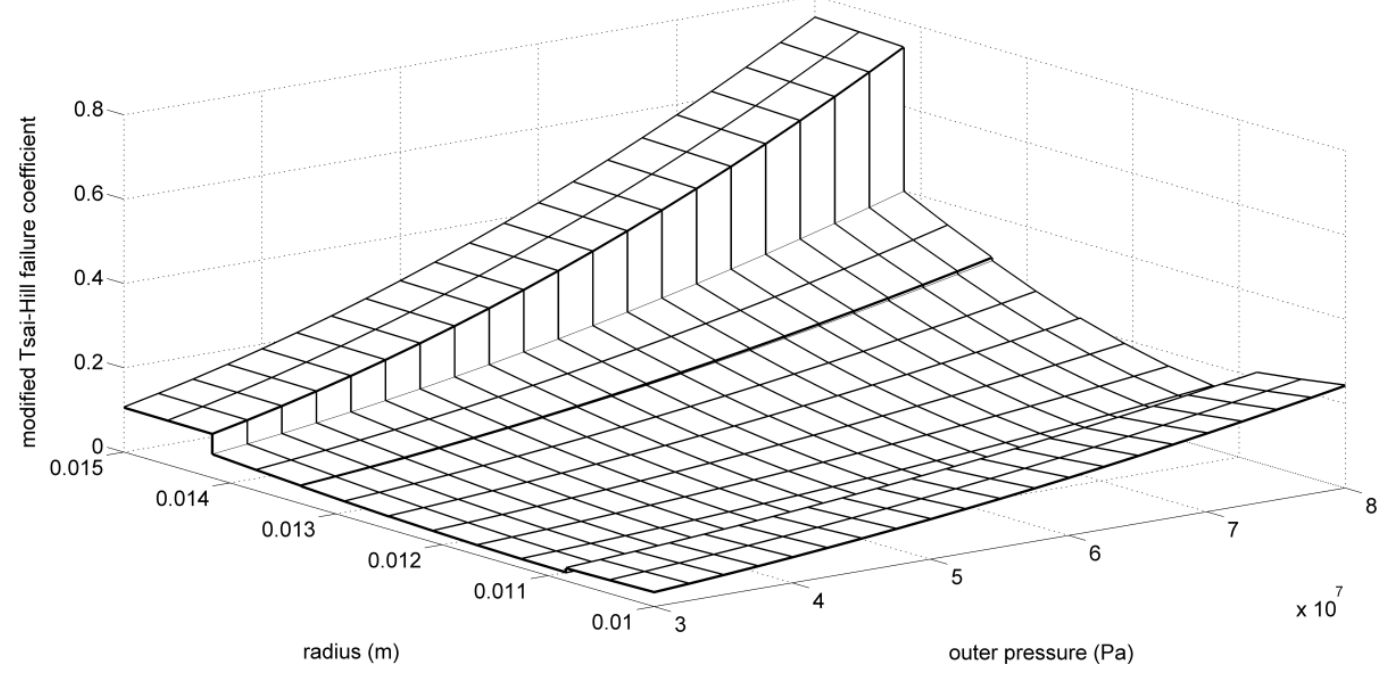

Figure 15. 


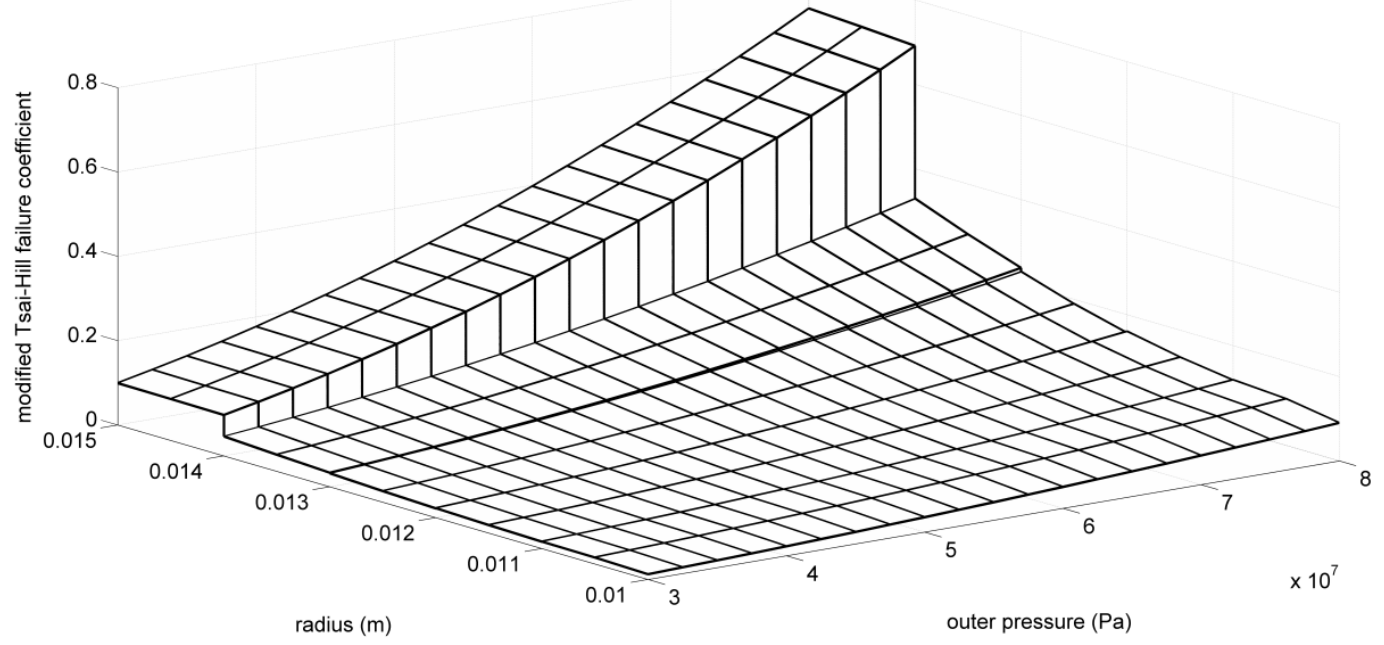

Figure 16. 